\title{
A Morphosyntactic Analysis of Patient-Subject Constructions in Chinese
}

Changsong Wang ${ }^{1,2}$, Mingming Zheng ${ }^{1}$

Beijing Institute of Technology ${ }^{1}$

Key Laboratory of Language, Cognition and Computation, Ministry of Industry and Information Technology ${ }^{2}$

\begin{abstract}
The exact nature and derivation of patient-subject constructions (PSC) in Chinese are still at dispute in literature. Based on the restriction of manner adverbial modification and the nonexistence of the manner reading of zenme 'how' observed in Chinese PSC, a morphosyntactic analysis has been provided. We argue that the seeming action verb $\mathrm{V}$ in PSC is not a real main verb, but a verbal root to be introduced into the derivation after syntax via external morphological merger. The real main verb of PSC in syntax is a covert light verb $\emptyset_{\mathrm{BEC}}$, which selects a nominal phrase (NP) as its specifier (Spec) and a resultative phrase (RP) as its complement. BECP is further selected by an aspect (Asp) head le. To satisfy the extended projection principle (EPP), the NP at [Spec, BECP] moves to the [Spec, TP] in syntax. After syntax, the resultative (R) head-moves to $\emptyset_{\mathrm{BEC}}$ at the phonological form (PF) to satisfy the phonological requirement of $\emptyset_{\mathrm{BEC}}$, forming $\mathrm{R}-\emptyset_{\mathrm{BEC}}$; then, a bare verbal root merges with $\mathrm{R}-\emptyset_{\mathrm{BEC}}$ at PF to denote the manner of the change of state. Due to the phonological requirement of $l e, \mathrm{~V}-\mathrm{R}-\emptyset_{\mathrm{BEC}}$ headmoves to le, producing the right order of PSC. The two elided forms of PSC can be derived similarly. This research suggests that covert light verbs and morphology may play an interactive role in the derivation of some "typical" constructions in Chinese.
\end{abstract}

\section{Keywords}

external morphological merger, morphosyntactic interface, restriction of manner adverbial modification, root, patient-subject constructions

Studies in Chinese Linguistics, Volume 41, Number 1, 2020, 33-72 DOI: 10.2478/scl-2020-0002 (C) 2020 Changsong Wang and Mingming Zheng. Studies in Chinese Linguistics is published by Sciendo on behalf of T.T. Ng Chinese Language Research Centre, Institute of Chinese Studies, The Chinese University of Hong Kong. This work is licensed under the Creative Commons Attribution-NonCommercial-NoDerivatives 4.0 International License. 


\section{Introduction}

\subsection{Patient-subject constructions and middle constructions in Chinese}

Patient subject is a term commonly used in traditional Chinese grammar (Ding et al. 1961: 29-34; Gong 1980; and so on). Patient-subject constructions (PSC) refer to a sentence with a patient as the subject, in which the agent is often omitted or unavailable. The past decades have witnessed much progress on the research of PSC in terms of classifications and derivations. A broad definition, for instance, may include many subtypes (Ding et al. 1961; Gong 1980; and so on). To be specific, Gong (1980) types sentences with a passive marker into PSC. However, further studies (i.e. Rong 2006; Huang et al. 2009; Dong 2015) suggest differentiating PSC from passive sentences, as they are distinct in several aspects. For instance, a sentence as in (1a) cannot be changed into a marked passive sentence (Gong 1980; Rong 2006), as shown in (1b). Meanwhile, an agent-oriented adverb such as guyi 'on purpose' is permitted in passive sentences, as in (1d), while it is not allowed in PSC (i.e., Dong 2015: 310), as in (1c). battle fight defeated LE 'The battle was defeated.'
a. Zhang da bai le. ${ }^{1}$
b. *Zhang bei da bai le. battle Pass fight defeated LE Intended: 'The battle was defeated.'
c. *Zhang guyi da bai le. battle on.purpose fight defeat LE Intended: 'The battle was defeated on purpose.'
d. Zhang bei guyi da bai le. battle Pass on.purpose fight defeated LE 'The battle got defeated on purpose.'

Cross-linguistically, PSC in Chinese are often compared with transitivity argument alternation sentences (Keyser and Roeper 1984; Cheng 1989; Levin and Rappaport 2005: 26; Ramchand 2013: 283; Yang and Cheng 2018; and so on), such as (2a, a') in English. Meanwhile, PSC are often compared with middle constructions, such as $(2 b)$ in French and (2c) in Italian, in which a reflexive (REFL) marker se/si is present (cf., Keyser and Roeper 1984; Sung 1994; Cheng and Huang 1994; Fagan 2009; Ramchand 2013: 283; Xiong 2018; Hu 2019; and so on).

\footnotetext{
1 The nature of le and guo in PSC is at issue in literature. For easy composition, we gloss them as LE and GUO. Other abbreviations are as follows: Asp(P): Aspect (Phrase); BEC(P): BECOME (Phrase); CL: classifier; DE: de; DurP: Duration Phrase; FrP: Frequency Phrase; Inch: Inchoative marker; NP: Nominal Phrase; Pass: passive marker; Perf: Perfective marker; $\mathrm{R}(\mathrm{P})$ : Resultative (Phrase); REFL: reflexive marker; TP: tense phrase; VR: Verb Resultative (Compound).
} 
(2) a. The glass broke.

(English)

a'. Tom broke the glass.

b. La Tour Eiffel se voit de loin. (French) the Tower Eiffel REFL see from afar 'The Eiffel Tower can be seen from afar.' (Fagan 2009: 94)

c. Qui, gli spaghetti si mangiano spesso. here the spaghetti REFL eat often 'Here spaghetti is often eaten.' (Cinque 1988: 554)

As to middle sentences, they are generally stative and nonepisodic (Keyser and Roeper 1984; Roberts 1986; Sung 1994; Cao 2005; Ackema and Schoorlemmer 2017; Xiong 2018; and so on). A widely accepted English middle sentence is shown in (3a) and its Chinese counterpart is (3b) (Keyser and Roeper 1984; Sung 1994; Cao 2004; Xiong 2018; and so on). As to the Chinese language, there is still no consensus on the exact relation between middle constructions and PSC. Semantically, both of them bear passive-like meaning without an overt passive marker. From this perspective, they may be loosely typed into the same category (Ding et al. 1961; Gong 1980; Cheng 1989; Ting 2006). Structurally, they differ in whether an additional marker, i.e., qilai, is involved (Sung 1994; Cao 2004, Cao 2005; Xiong 2018; Hu 2019). The qilai in (3b) is compulsory, while it is not permitted in PSC. Meanwhile, le is obligatory in PSC, while it is restricted from occurring in middles, as shown in (3c). Therefore, following Keyser and Roeper (1984), Cheng and Huang (1994: 207-208), and Dong (2015), we distinguish Chinese middles from PSC in this article. As the demarcation of PSC is still at dispute (Ding et al. 1961; Gong 1980; Zhan 1992; Rong 2006; Dong 2015), we select widely accepted PSC to study, which is formalized in (4) and illustrated in (5). Under certain occasions, either the verb (V) or the resultative (R) in (4) can be omitted, but not both, as detailed in Section 5.4. Sentences like (5) are often named as transitivity alternation sentences in literature (i.e., Cheng 1989; Cheng and Huang 1994; and Yang and Cheng 2018). However, as no transitivity alternation is shown to be involved in the derivation of PSC, we stick to the traditional term PSC, but it is taken with the narrowest definition as formalized in (4). Unless noted otherwise, PSC in this article denote PSC in Chinese.

(3) a. The book reads easily.

b. Zhe ben shu du qilai rongyi. this CL book read get.up easy

'This book reads easily.'

c. ??*Zhe ben shu du qilai rongyi le. this CL book read get.up easy LE

(4) $\mathrm{NP}_{\text {Patient }}+\mathrm{V}+\mathrm{R}($ esultative $)+l e$ 
a. Fan chi wan le.

meal eat done LE

'The meal has got finished from eating.'

b. Yifu xi ganjing le.

cloth wash clean LE

'The clothes have got clean from washing.'

\subsection{The analyses of middle constructions and PSC in Chinese}

The analyses of PSC are often related to the analyses of middle constructions. The syntactic approach and the lexical approach are two major approaches to middle constructions, both aiming to explain the disappearance of agents. As noted in the literature, agent-oriented adverbs are restricted from occurring in middles (i.e., Roberts 1986; Sung 1994; Ramchand 2013; Dong 2015; Hu 2019), as shown in (6a, b). This means that agents in middles are not involved or suppressed in some way (Roberts 1986; Fagan 1988, Fagan 2009; Stroik 1992; Sung 1994; and so on). The syntactic approach derives middles via movement of a postverbal nominal phrase (NP) to a preverbal position in the syntax (i.e., Keyser and Roeper 1984; Stroik 1992; Hoekstra and Roberts 1993; Sung 1994; and so on). ${ }^{2}$ This movement analysis has been adopted to explain PSC. Under this approach, the agent is suppressed or demoted, and the patient moves to the subject position, either for case or for feature checking (i.e., Wang 2008; Yang and Cheng 2018). In agreement with the lexical approach (Fagan 1988, Fagan 2009; Ackema and Schoorlemmer 1994), Chinese middles are derived similarly through a presyntactic operation on the verbs (Cheng 1989; Ting 2006). A new third analysis of Chinese middles is to assume that a bare root is merged with a silent light verb $\mathrm{V}_{\mathrm{BEC}(\mathrm{OME})}$ under the framework of distributed morphology (DM) (Hu 2019). All these approaches are successful in some aspects, leaving others unexplained (cf., Sung 1994: 62-67; Yang and Cheng 2018). Similar problems may emerge if they are extended to the analysis of PSC. For instance, a movement-based syntactic approach cannot explain why PSC may lack corresponding agent-subject sentences (Gong 1980: 342), as shown in (7a). On the other hand, the lexical approach needs to explain the possible existence of an agent in some cases of PSC (Zhu 1982: 99), as in (7b). A key problem for all these approaches, from our perspective, is that they cannot explain the restriction of manner adverbial modification on the action verbs in PSC, as detailed in Section 3.

a. *The book sold easily deliberately.

b. *Zhe ben shu guyi mai qilai rongyi. this CL book deliberately sell get.up easily Intended: '*This book sells easily deliberately.'

2 Both Stroik (1992) and Hockstra and Roberts (1993) support the movement hypothesis but they differ in how the agent role is absorbed. For Stroik (1992), the agent role is assigned to a big ungoverned PRO and demoted to a VP-adjunct position. For Hoekstra and Roberts (1993), the implied agent is perceived through a little pro, which is claimed to take the VP-internal subject position. 
(7) a. Shenghuo shuiping tigao le. living standard improve LE 'The living standard has improved.'

b. Shu ta mai wan le. book he sell done LE

'The books have been sold out by him.'

The remainder of the article is organized as follows. In Section 2, we first review the four main constituents of PSC. The restriction of manner adverbial modification in PSC is discussed in Section 3. The theoretical prerequisites are sketched in Section 4. Based on the restriction of manner adverbial modification, this article provides a morphosyntactic analysis of PSC in Section 5. Section 6 is the conclusion.

\section{The constituents of PSC in Chinese}

\subsection{The preverbal NP}

The preverbal NP is normally an affected participant as a patient, which exercises no volition or control. A patient is often interchangeably used with a Theme, which refers to entities undergoing the actions of movement, experience, or perception (Kearns 2011: 207-208; Tang 2019: 89). Dowty (1991) types patient and theme as a Proto-Patient. The contributing properties for a Proto-Patient generally consist of five factors: (i) undergoing change of state; (ii) incremental theme; (iii) causally affected by another participant; (iv) stationary relative to movement of another participant; (v) not existing independently of the event (Dowty 1991: 572). The NP boli 'glass' in (8), for instance, shows some of these properties. As the patienttheme distinction is not easy (Dowty 1991; Kearns 2011: 215) and unnecessary for current analysis, we follow the tradition in Chinese to call it patient in this article. A support for this is that when the preverbal NP is questioned with shenme 'what', the answer tends to be interpreted as a patient, as in (9Ba), but not other theta-roles (i.e., instrument) (Zhan 1992: 198-199), as in (9Bb).

(8) Boli da sui le. glass hit break LE

'The glass has been broken.'

(9) A. Shenme da sui le? what hit break LE 'What was broken?'

B. a. Boli da sui le. glass hit break LE 'The glass was broken.'

b. ${ }^{*}$ Chuizi da sui le. hammer hit break LE Intended: 'The hammer was broken.' 
The NPs in PSC are constrained semantically, as is the case in middle constructions (cf., Zhu 1982; Fagan 1988; Sung 1994; Cao 2004, Cao 2005; Rong 2006; and so on). Most of them are inanimate and third person-denoting units (Gong 1980; Zhu 1982; Rong 2006), such as fan 'meal', yifu 'clothes', and boli 'glass' in (5) and (8). Otherwise, sentences may deteriorate or the intended meaning cannot be expressed, as in the contrast shown in (10a) and (10b). The xiaomao 'kitten' in (10a) tends to be interpreted as an agent instead of as a patient. ${ }^{3}$ Meanwhile, the preverbal NPs in PSC are often interpreted as definite/specific or generic (Ding et al. 1961; Zhu 1982; Zhan 1992), as in the contrast between (11a, c) and (11b). This might be related to the properties of subjects in Chinese, which need to be definite/specific or generic (Chao 1968; Zhu 1982), unless they denote a number phrase (Li 1998; Tang 2019: 76-78) or are licensed under certain special contexts (i.e., Fan 1985; Lee and Wu 2019: 304-307; and so on).
a. ?Xiaomao lin shi le.
kitten soak wet LE
Intended: 'The kitten got soaked.'
b. Yifu lin shi le.
clothes soak wet LE
'The clothes got soaked.'

(11) a. Yifu shoushi hao le.

clothes collect finished LE

'The clothes have got ready from collecting.'

$\begin{array}{cllll}\text { b. ?Yi jian yifu } & \text { shoushi hao le. } \\ \text { one } \mathrm{CL} & \text { clothes collect finished } & \text { LE }\end{array}$

'A piece of clothes has got ready from collecting.'

$\begin{array}{llll}\text { c. Naxie yifu } & \text { shoushi hao le. } \\ \text { those clothes collect finished } & \text { LE }\end{array}$

'Those clothes have got ready from collecting.'

\subsection{The seeming action verb $\mathrm{V}$}

Not all verbs can occur in PSC, as frequently noted in the literature. Some selectional restrictions are imposed on the verbs (cf., Cheng 1989; Zhan 1992; Yang and Cheng 2018). As in middle constructions (Sung 1994), stative, psych, and intransitive verbs such as $s h i$ 'be', xihuan 'like', and $s i$ 'die' cannot occur in PSC. The verbs in PSC are mainly action verbs, being transitive, as in (5), (8), and

3 As noted by a reviewer and pointed out by Gong (1980: 336), Lü (1987: 2), and Zhan (1992: 202), the inanimate requirement is only a tendency and can be violated occasionally, as zhegeren "this person' in (ib) can be interpreted as a patient.
(i) a. Wo zhao ge ren.
b. Zhe ge ren zhaozhao le.
'I want to find a person.'
this $\mathrm{CL}$ person find.on LE
'The person got found.' 
(11), or ditransitive, as in (12). We detail the properties of these action verbs in Section 3.
a. Shu fang hao le. book put finished LE 'The book has been ready from storing.'
$\begin{array}{llll}\text { b. Qian cun hao le. } & \\ \text { money deposit finished } & \text { LE }\end{array}$
'The money has been ready from depositing.'

\subsection{The resultative $\mathrm{R}$}

Verbs in PSC are normally immediately followed by resultative complements (i.e., Lü 1987; Cheng 1989; Packard 2000; and so on), as the hao 'finished' in (12a, b). Although resultative complements may have no overt phonetic forms, marked as $\emptyset_{R}$ in (13), they should be there if viewed semantically. The units $V+R$ together form an accomplishment verb in PSC. For instance, the verb $x i$ 'wash' may incur a potential result from the action. In most cases, the washing consists of an action process and an associated result, which is normally ganjing 'clean', as in (14a). Similarly, the action $x i$ 'wash' may denote a result such as hao/wan/guo 'finished', as in (14b). Generally, there are two types of result-denoting Rs: specific results as in (14a, 15a); or general results as in (14b, 15b). If PSC aim to express a general result, its complement can sometimes be dropped (cf., Chao 1968: 246), as in (13). However, if PSC intend to denote a specific result, the adjective must be there. Otherwise, the specified result meaning cannot be expressed.

$$
\begin{array}{lll}
\text { Yifu xi } \emptyset_{\mathrm{R}} & \text { le. } \\
\text { clothes wash } & \text { LE } \\
\text { 'The clothes have undergone the process of washing.' }
\end{array}
$$

(14) a. Yifu xi ganjing le.

clothes wash clean LE

'The clothes have got clean from washing.'

b. Yifu xi hao/wan/guo le.

clothes wash finished LE

'The clothes have got ready from washing.'

(15) a. adjectives denoting specific results of $x i$ 'wash':

ganjing 'clean', sui 'broken', and so on

b. adjectives denoting general results of $x i$ 'wash': hao/wan/guo 'finished', and so on

Semantically, not all adjectives can be the Rs in PSC. The result-denoting adjectival Rs are required to be capable of modifying the preverbal nouns, as the xiao 'small'

4 As discussed in Section 5.3.2, guo here refers to the end of an action. It is often noted as guo in Chinese literature, which is distinct from the experiential aspect marker guo (Kong 1986; Lü 1999; and so on). 
in (16). If an adjective, $a i$ 'short' for instance, cannot modify the preverbal noun, as in (17a), it cannot occur in PSC either, as in (17b).
a. xiao yifu small clothes
b. Yifu xi xiao le. clothes wash small LE.
'The clothes have got small from washing.'
(17) a. *ai yifu
short clothes
b. *Yifu xi ai le.
clothes wash short LE.

Intended: 'The clothes have got short from washing.'

\subsection{Sentence-final le}

Compared with other constituents, the sentence-final le in PSC has received relatively less attention in the literature. Being obligatory, le cannot be deleted (Dong 2015: 311; Yang and Cheng 2018; and so on); otherwise, the original meaning in PSC disappears and the sentence may become ungrammatical (cf., Keyser and Roeper 1984), as in (18b), or turn imperative, as in (18c). Though le locates at the final position in PSC, it should not be analyzed as a sentence-final particle. Following Dong (2015), Yang and Cheng (2018), Paul (2014), and Pan (2017, 2019b: 16-17), we analyze the le in PSC as an aspect (Asp) marker $l e_{1}$, which is different from a sentence-final particle le (Chao 1968; Li and Thompson 1981).

Despite this, as noted by an anonymous reviewer, we cannot deny the possibility that the sentence-final $l e$ in PSC can be a conglomeration of perfective aspect $l e_{1}$ and sentence-final particle le (Chao 1968; Lü 1999: 351-359; Zhu 1982: 209-210; Lu 1991; Tang 2019). One point is clear, however, le must not be a sentence-final particle only. The reason is simple. A sentence-final particle cannot make a sentence grammatical or ungrammatical. It normally helps to complete a sentence (Kong 1986: 274; Lu 1991; Tsai 2008b), as shown in (19a, b). As the sentence without $l e$ would be ungrammatical, as in (18b), or turn into an imperative, as in (18c), the le in PSC should not be a sentence-final particle only. We discuss the details of le in Section 5.3.2.
a. Yifu xi ganjing le. clothes wash clean LE
'The clothes have got clean from washing.'
b. ??*Yifu xi ganjing.
clothes wash clean
Intended: 'The clothes have got clean from washing.'
c. Yifu xi ganjing!
clothes wash clean
'Wash the clothes clean!'



a. Wo xi hao le yifu le.
I wash finished LE clothes LE
'I have washed the clothes.'
b. \#Wo xi hao le yifu.
I wash finished LE clothes
Intended: 'I have washed the clothes.'

In the following section, we explore the restrictions on the action verbs in PSC.

\section{Restrictions on the action verbs in PSC}

Before discussing the derivation of PSC, it is worth noting that the verbs in PSC behave differently from normal action verbs, and they are somewhat restricted from being modified by manner adverbials, as detailed below.

\subsection{The restriction of manner adverbial modification}

Manner adverbials are normally used to modify action verbs, and they often describe how actions are carried out (Mittwoch et al. 2002), as shown with the underlined words in (20).

(20) a. She walked slowly away.

b. She departed very hastily.

c. We examined the damage carefully.

(Mittwoch et al. 2002: 670)

Similarly, manner adverbials in Chinese describe how the action encoded in a verb is implemented ( $\mathrm{Li}$ and Thompson 1981; Yip and Rimmington 2016), as in (21). They are often marked with the adverbial marker -de 地. For instance, the manmande 'slowly' in (21a) describes the manner of the action dakai 'open'. The henkuaide 'quickly' in (21b) illustrates how the meal is eaten. The huhude 'howlingly' in (21c) expresses the way in which the wind blows.
a. Ta manmande da kai le chuanghu. he slowly open open LE window 'He opened the window slowly.'
b. Ta henkuaide chi wan le fan. he quickly eat finished LE meal 'He finished the meal quickly.'
c. Leng feng huhude chui. cold wind howling blow 'The cold wind blew howlingly.'

Normally, Chinese manner adverbials are not restricted when they are used as modifiers of action verbs; however, they are barred from occurring in some structures, i.e., the resultative V-de constructions (Wang 2014) and the flip-flop sentences (Wang and Chin 2016), as respectively shown in (22a) and (22b). 
a. *Tom dashengde xiao de duzi tong. Tom loudly laugh DE stomach ache Intended: 'Tom got stomachache from [his] loud laughing.' (Wang 2014: 115)

b. *Yi guo fan dakoude chi san ge ren. one CL rice gulp eat three CL people Intended: 'One pot of rice is for three persons to eat in gulps.' (Wang and Chin 2016: 50)

Interestingly, PSC seem to observe the same manner restriction, as shown in (23b), in which the manner adverbial xunsude 'quickly' cannot modify the verb $x i$ 'wash'. In contrast, manner adverbials are free to occur in sentences with an agent as the subject, as in (23a).
a. Mama xunsude xi ganjing le yifu. mother quickly wash clean LE clothes 'The mother quickly washed the clothes clean.'
b. *Yifu xunsude xi ganjing le. clothes quickly wash clean LE Intended: 'The clothes have turned clean from washing quickly.'

Similarly, the action-oriented adverbial luanqibazaode 'messily' can modify the verb sai 'stuff' in (24a) (Yip and Rimmington 2016). However, an action-oriented adverbial in PSC may behave differently, as pengdeyisheng 'with a bang' in (24b) can only refer to the adjective $s u i$ 'broken', but not the action $d a$ 'hit'. These suggest that the action verbs in PSC may be distinct from normal action verbs.
a. Ta ba yaodai de dongxi luanqibazaode saijin beibao li. he BA want.take DE things messily stuff.into rucksack inside 'He stuffed the things he wanted to take messily into [his] bag.' (Yip and Rimmington 2016: 171)
b. Boli pengdeyisheng da sui le. glass with.a.bang hit broken LE 'The glass was broken with-a-bang.'

\subsection{The nonavailability of manner 'zenme'}

The restriction of manner adverbial modification can also be evidenced with the way of questioning with zenme 'how'. As noted by Tsai (2007, 2008a), the interrogative how in English has at least two interpretations: one is manner/ instrumental reading; and the other is causal reading, as shown, respectively, in (25) and (26).

(25) A: How did John handle this matter?

B: a. Quite skillfully, I think.

[Manner]

b. By pulling quite a few strings.

(Tsai 2008a: 84 [1]) 
(26) a. How come John arrived so late?

[Causal]

b. How is it that John arrived so late?

[Causal] (Tsai 2008a: 84 [2])

Similarly, zenme 'how' in Chinese has two readings. One is manner/instrumental reading, and the other is causal/denial reading (Tsai 2007, Tsai 2008a; and so on), as in $(27 a, b)$.
a. Akiu zenme qu Taipei?
Akiu how go Taipei
'How will Akiu go to Taipei?'
[Instrumental/Manner]
b. Akiu zenme qu le Taipei?
Akiu how go LE Taipei
[Causal/Denial]
'How come Akiu went to Taipei?'
(Tsai 2008a: 85)

Although both manner reading and causal reading are available for zenme 'how' in normal Chinese sentences, these readings are surprisingly unavailable in certain structures. For instance, only causal/denial reading of zenme 'how' is available in resultative V-de constructions (Wang 2014), as in (28Ba, Bb). Similarly, the manner reading of zenme 'how' is barred from occurring in a flip-flop sentence (Wang and Chin 2016), as shown in (29Ba).

(28) A. Ta zenme pao-de hen lei?

he how run DE very tired

'How did he get tired from [his] running?'

B. a. ${ }^{*} \mathrm{Ta}$ feikuaide pao.

he fast run

[*Manner]

Intended: 'He ran fast.'

b. Yinwei ta hen zhaoji.

because he very hurried

'Because he was in such a hurry.'

(Wang 2014: 118-119)

(29) A.San ge ren zenme chi yi guo fan? three CL people how eat one CL rice

'How could three people eat one pot of rice?'

B. a. *San ge ren manmande chi yi guo fan. three CL people slowly eat one CL rice

[*Manner] Intended: 'Three people slowly ate a pot of rice.'

b. Shide, chi bu wan. yes eat not finish

'No, they could not eat all of it.'

(Wang and Chin 2016: 50)

Similarly, only the causal/denial reading of zenme 'how' is permitted in PSC, as in $(30 \mathrm{Bb}, \mathrm{Bc})$. The manner reading, in contrast, is not acceptable, as in $(30 \mathrm{Ba})$. 
(30) A.Fan zenme chi wan le?

meal how eat finish LE

'How could the meal be eaten up?'
B. a. *Fan manmande chi wan le. meal slowly eat finish LE.
Intended: 'The meal was eaten up slowly.'
b. Shi, fan bu yinggai dou chi wan le. [Denial] yes meal not should DOU eat finish LE 'No, the meal should not be all eaten up.'
c. Yinwei wo hen e. because I very hungry
'Because I was very hungry.'
[*Manner]
[Causal]

Moreover, Tsai $(2007,2008$ a) points out that a modal can tease apart the manner reading from the causal reading. According to him, when the interrogative adverb zenme 'how' is put after a modal such as keyi 'can', the sentence is to question a manner, as in (31a). If zenme 'how' is put in front of the modal, the question implies a causal or denial reading, as in (31b). Actually, these two readings of zenme 'how' have a morphological difference. The postmodal zenme 'how' in manner questions can alternate with zenme-yang 'howmanner', as in (31a), while the premodal zenme 'how' in causal questions cannot, as in (31b).
a. Akiu keyi zenme(-yang) qu Taipei?
Akiu can how(-manner) go Taipei 'How can Akiu go to Taipei?'
b. Akiu zenme(*-yang) keyi qu Taipei?
Akiu how(-manner) can go Taipei
'How come Akiu could go to Taipei?'
'Akiu can't/shouldn't go to Taipei.'
[Instrumental]
[Causal/Denial]

Taking modal hui 'can' as a test in PSC, we will find that zenme 'how' can only be put before $h u i$, as in (32a), but not after hui, as in (32b). This also shows that only causal/denial reading is available in PSC.
a. Yifu zenme hui xi ganjing le? clothes how can wash clean LE
'How come the clothes got clean from washing?'
b. *Yifu hui zenme xi ganjing le? [*Manner/Instrumental] clothes can how wash clean LE
Intended: 'In what way can the clothes get clean from washing?'

\subsection{Some counterexamples to the restriction?}

An anonymous reviewer notes that the generalization on manner adverbial modification is compatible with the data presented in the paper, but there are too many exceptions, in which manner adverbials can occur. The reviewer 
lists (33) and (34) as examples in PSC and (35) and (36) as examples in phrasal de-resultatives. ${ }^{5}$

$\begin{array}{llllll}\text { Zhuozi zao jiu } & \text { qiaoqiaode } & \text { ca ganjing } & \text { le. } \\ \text { table early already } & \text { quietly } & \text { wipe clean } & \text { LE } \\ \text { 'The table has already been wiped clean quietly.' } & \end{array}$

(34) Zhuozi zao jiu yizhangyizhangde ca ganjing le. table early already table.by.table wipe clean LE 'The table has already been wiped clean quietly.'

(35) ?Tom dashengde xiao de duzi dou tong le. Tom loudly laugh DE stomach all ache LE

'Tom laughed so loudly that he even got stomachache.'

(36) Tom fafengside xiao de duzi dou tong le. Tom crazily laugh DE stomach all ache LE 'Tom laughed so crazily that he even got stomachache.'

According to the reviewer, the unacceptable examples cited in this article do exist, but they are bad because something is missing or could be improved if a different manner adverbial is selected. For instance, if the manner adverbial in (23b) is replaced by a more appropriate one, as in (37) and (38), the sentences will sound much better.

(37) Yifu xixinde xi ganjing le. clothes carefully wash clean LE 'The clothes have been washed carefully.'

(38) Yifu zixide bu hao le. clothes carefully repair well LE 'The clothes have been sewed up carefully.'

5 We don't concur with the reviewer's judgment on (35) and (36). Both are not good for us. There might be one issue that helps to explain the reviewer's judgment on (35) and (36), namely, a possible pause involved in these sentences. We and our informants feel that we tend to pause a bit after dashengde 'loudly' and fafengside 'crazily' in (35) and (36). If a pause is indeed involved, the manner adverbial is not modifying the $\mathrm{V}$ directly but may function as a predicate itself or as a modifier of another copied verb of xiao, as suggested by $\mathrm{Li}$ (1963). Li notes that manner adverbials are seldom used in $\mathrm{V}$-de constructions and (ia) seems to be an exception. Li, however, further notes that (ia) is not a counterexample, and menzhetou 'with his head down' in (ia) is not a modifier of zou in zou-de. There may be two zou 'walk' in (ia) and menzhetou modifies the first zou, but not the zou in zou de feikuai 'walk fast'. In this line, (ia) can be analyzed as (ib). The pause in (35) and (36) functions similarly to the first zou 'walk' in (ib).
(i) a. Ta menzhetou zou de feikuai.
he with.head.down walk DE very.fast
'He walked very fast with his head down.'
b. Ta menzhetou zou zou de feikuai.
he with.head.down walk walk DE very.fast
'He walked very fast with his head down.' 
The reviewer agrees that the action-oriented adverbial in (24b) is more likely to modify the R sui 'broken' of the verb resultative (VR) compound dasui 'hitbroken'. This is because the noise peng 'bang' is associated with the process of sui 'broken'. However, if the adverbial in (24b) is changed into yibuxiaoxin 'carelessly', as in (39), the sentence is good, as 'carelessly' can be associated with the verb $d a$ 'hit'. It seems that the part that the adverbial is associated with depends on the semantic content of the adverbial and the semantic content of either the $\mathrm{V}$ or the R.

$\begin{array}{llll}\text { Boli yibuxiaoxin da sui } & \text { le. } \\ \text { glass carelessly hit broken } & \text { LE } \\ \text { 'The glass was broken carelessly.' }\end{array}$

The same applies to the manner reading of zenme. According to the reviewer, it is true that $(30 \mathrm{~A})$ can only take $(30 \mathrm{Bb})$ and $(30 \mathrm{Bc})$ as answers, but it is determined by the question in (30A). If the question takes the form of (40A), (40B) would be an acceptable answer. Despite this, both anonymous reviewers note the possibility that we may rule out (40B) as our PSC is defined with the le at the end of a sentence (see [4]), but not the de.
A: Fan shi zenme chi wan de? rice is how eat finished $\mathrm{DE}$ 'How on earth was the rice eaten up?'
B: Shi manmande chi wan de. is slowly eat finished $\mathrm{DE}$ 'It was eaten up slowly.'

We thank both reviewers for pointing out these counterexamples to us. Yes, we agree that most of them are acceptable. But, on closer scrutiny, as suggested by both reviewers, we find they are either not real instances of PSC, or the adverbials are not describing the manners of the action verbs, but referring to an agent or result, as detailed below.

Let us consider the first possibility. Studying the counterexamples listed above, we find that manner adverbials do occur in some focus constructions (i.e., Hole 2004), as in (33-34) and (40B). (40B) is the shi...de construction, and it is a typical focus construction in Chinese (Teng 1979; Cheng 2008; Paul and Whitman 2008). Surprisingly, if questioned with zenme 'how' in the shi... de construction, manner reading becomes prominent, as noted by Tsai (2007: 202). This, however, cannot deny the existence of the restriction on the manner adverbial modification in PSC, as the shi...de focus construction is distinct from PSC. With the insertion of shi...de into PSC, as in (40B), the internal structure might have been changed.

Similarly, a focus-sensitive adverb such as jiu 'already' is found in (33-34) and a dou 'all' is found in (35-36), which help to improve the acceptability of 
these sentences. As predicted, if zao jiu are deleted in (33-34), the sentences would become less acceptable, as shown in (41-42). Similarly, if the dou is deleted in (35-36), the acceptable sentences judged by an anonymous reviewer would deteriorate, as shown in (43-44).

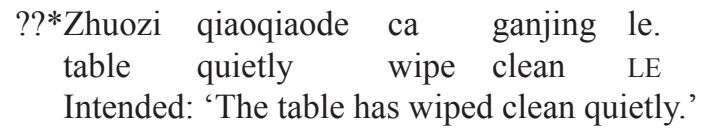

??*Zhuozi yizhangyizhangde ca ganjing le.
table table.by.table wipe clean LE
Intended: 'The table has wiped clean one by one.'

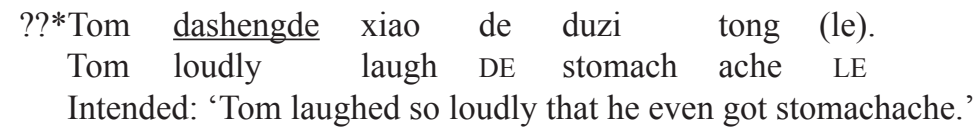

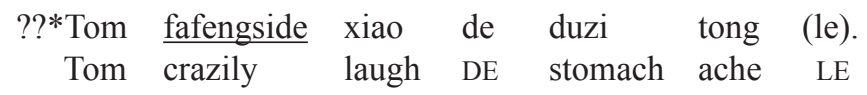

Intended: 'Tom laughed so crazily that he even got stomachache.'

We agree with the reviewer that yizhangyizhangde 'table by table' in (34) can refer to the manner of the action $c a$ 'wipe'. However, we show different judgment with him/her on the reference of qiaoqiaode 'quietly' in (33). We and our informants tend to interpret qiaoqiaode 'quietly' as an adverbial referring to a hidden agent (cf., Jackendoff 1972: 49; Li and Thompson 1981: 325-327; Zhan 1992: 197-198; Yang and Cheng 2018: 659), as shown in (45). Even if qiaoqiaode refers to the action of wiping in (45), it is not a problem as the whole sentence has changed into a topic sentence, with zhuozi 'table' as the topic and the agent wo/ta 'I/he' as the subject (Gong 1980: 341-342; Pan and Han 2005: 10-11; Hu 2019: 97-98).

$\begin{array}{lllllll}\text { Zhuozi } & \text { wo/ta } & \text { zao } & \text { jiu } & \text { qiaoqiaode } & \text { ca ganjing } & \text { le. } \\ \text { table } & \text { I/he } & \text { early } & \text { JIU } & \text { quietly } & \text { wipe clean } & \text { LE } \\ \text { 'As for the table, I/he have/has wiped it clean quietly.' } & \end{array}$

The exact derivation of the above focus-related sentences, as shown in (33-34, 40B), is still open and we cannot go into the details due to space limit. The verbs in these focus constructions may be real action verbs, which are distinct from the verbs in PSC.

Syntactically, with the help of a focus-sensitive adverb, the manner adverbials in (33-34) may undergo reanalysis, forming an independent constituent of their own (i.e., a predicate) (Huang 1982: 49-50) or forming a new constituent with the focus-sensitive adverb. Accordingly, a new independent prosodic/intonation phrase has been established prosodically (cf., Chen 1987; Truckenbrodt 1999: 223-224; Féry 2013). 
Similar to the interpretation of qiaoqiaode 'quietly' in (33), we tend to interpret xixinde 'carefully' in (37), zixide 'carefully' in (38), and yibuxiaoxin 'carelessly' in (39) as adverbials referring to a hidden agent (cf., Jackendoff 1972; Li and Thompson 1981; Travis 1988; Yip and Rimmington 2016: 170-172; and so on). Actually, (37) and (39) are not good for us and our informants. Suppose they are acceptable, the adverbials should refer to hidden persons, instead of the actions. The addition of an agent in (37) can help to improve its acceptability, as shown in (45). Interestingly, the manner reading in (45) is still available, even though the adverb zao jiu is deleted, as pointed out by the reviewer. On this occasion, however, the sentence in question is no longer an instance of PSC, but a topic sentence with an agent as its subject.

As discussed above, action verbs in PSC are distinct from normal action verbs. They are somewhat restricted. This puzzle can receive a natural explanation with a late insertion hypothesis in the context of DM, as detailed in Section 5. Before this, we first briefly introduce the defining properties of DM.

\section{Theoretical prerequisites}

Distinct from previous analyses of PSC, this article adopts a morphosyntactic perspective. To be specific, we use some key notions in DM (Halle and Marantz 1993; Harley and Noyer 1999; Embick 2015). Adopting the basic organization of "principles-and-parameters" (Chomsky 1995: Ch. 1), DM adds a new level called Morphological Structure (MS), which is an interface between syntax and phonology, as shown in (46). The terminal elements in D-Structure (DS), S-Structure (SS), and Logical Form (LF) consist of complexes of grammatical features, and they are supplied with phonological features only after vocabulary insertion at MS. "MS is a syntactic representation that nevertheless serves as a part of the phonology, where 'phonology' is broadly conceived as the interpretive component that realizes syntactic representations phonologically" (Halle and Marantz 1993: 114). MS is a level with its own principles. Morphemes may be inserted at MS to meet universal or language-specific well-formedness conditions (Halle and Marantz 1993: 115).

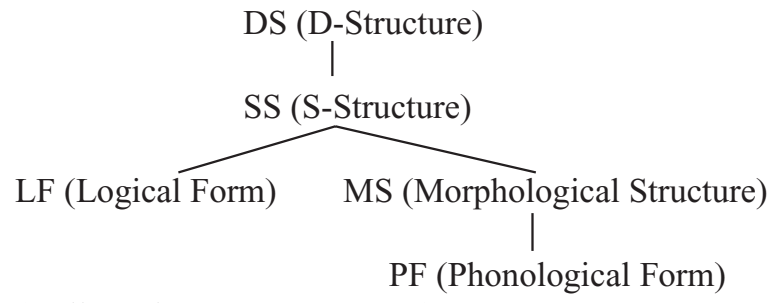

(Halle and Marantz 1993:114)

Distinct from other morphological theories, in which morphology only focuses on the formation of words and is sharply separated from syntax 
(Jensen 1990; Aronoff 1994), DM proposes that morphology is not only concentrated on a single component of the grammar but is distributed among several different components (Halle and Marantz 1993). In this line, there is no divide between the construction of words and the construction of sentences. This is the "syntactic hierarchical structure all the way down", one of the three distinguishing properties of DM. The other two properties are "underspecification" and "late insertion" (Halle and Marantz 1994: 275-276). Underspecification means that the identifying features of the Vocabulary Item must be a subset of the features at the terminal nodes and the inserted item ought to be the most highly specified one. Late insertion indicates that phonological features are supplied after syntax via the insertion of vocabulary items into terminal nodes. These postsyntactic morphologyspecific operations can help to explain some mismatches between syntax and morphology. We mainly use the notion of late insertion to explain the restriction of manner adverbials in PSC. We take the original hypothesis that Roots (i.e., $\sqrt{ } \mathrm{CAT}, \sqrt{\mathrm{WASH}}$ ), as well as functional categories (i.e., $n, v$ ) and other inflectional affixes (i.e., $-s$ ), can be inserted via late insertion (Halle and Marantz 1993; Haugen and Siddiqi 2013). For ease of composition, however, in this article, we just illustrate how the action verb $\mathrm{V}$ is inserted into the sentence via late insertion.

Meanwhile, to satisfy certain morphological requirements in the derivation of PSC, we borrow and extend the term Morphological Merger (MM). MM, proposed first by Marantz (1984), was originally a principle of well-formedness between levels of representation in syntax. In the paper by Marantz (1988), it was generalized as in (47). For a more recent discussion of $\mathrm{MM}$ at the phonological structure, please refer to Embick and Noyer 2001, 2007.

(47) Morphological Merger (Marantz 1988: 261)

At any level of syntactic analysis (D-structure, S-structure, phonological structure), a relation between $\mathrm{X}$ and $\mathrm{Y}$ may be replaced by (expressed by) the affixation of the lexical head of $\mathrm{X}$ to the lexical head of $\mathrm{Y}$.

Inspired by Huang (2006), in this article, we extend the application of MM and assume that MM can also take place by externally merging a root morphologically with a syntactically preexisting light verb. This is something similar to External Merge (Chomsky 2004) or Direct Merge (Embick 2004: 372), which is operating in syntax. To distinguish it from Marantz's MM, we dub it “External Morphological Merger" (EMM).

\section{A morphosyntactic approach to PSC}

Section 3 demonstrates that the action verbs in PSC are different from normal action verbs. Considering this observation, this section presents a 
morphosyntactic analysis of PSC. Before the presentation, we review some relevant analyses on restricted action verbs, which may shed some light on the current analysis.

\subsection{V merged as an adjunct after syntax}

As shown in Section 3, the restriction of the manner adverbial modification and the nonexistence of manner zenme 'how' reading are observed not only in PSC but also in some other constructions in Chinese, such as the resultative and descriptive V-de constructions (Wang 2014), flip-flop constructions (Wang and Chin 2016), and "V+DurP" [duration phrase (DurP)] constructions (Wang and Chin 2018). To explain those restrictions, a morphosyntactic approach has been adopted in Wang 2014 and Wang and Chin 2016, 2018. This line of research is actually inspired by Huang's (2006) adjunct analysis of verbs in Chinese resultative $\mathrm{V}$-de constructions, in which the action verb $\mathrm{V}$ is no longer analyzed as a main predicate as previously proposed in literature (i.e., Huang 1988, Huang 1992). Adopting the event structure templates (Rappaport Hovav and Levin 1998; Rappaport Hovav and Levin 2001), as in (48-49), Huang (2006, 2015) analyzes the verb $\mathrm{V}$ as an adjunct of the functional head -de, which may be instantiated as a light verb, i.e., BEC(OME) or CAUSE (Huang 1997; Lin 2001), as respectively shown in (50) and (51), which are illustrations of (48) and (49b).

(48) The Inchoative Template:

$[$ BECOME $<$ MANNER> $[\mathrm{X}<$ STATE $>]]$

(Huang 2006: 23)

(49) a. The 'pure' causative template:

$$
\text { [X CAUSE [BECOME } \left.\left.{ }_{<M A N N E R>}[\mathrm{y}<\text { STATE }>]\right]\right]
$$

b. The 'causing-with-a-manner' causative template:

$\left[\mathrm{x}\right.$ CAUSE ${ }_{<M A N N E R>}[$ BECOME $[\mathrm{y}<$ STATE $\left.>]]\right]$

(Huang 2006: 24)

(50)

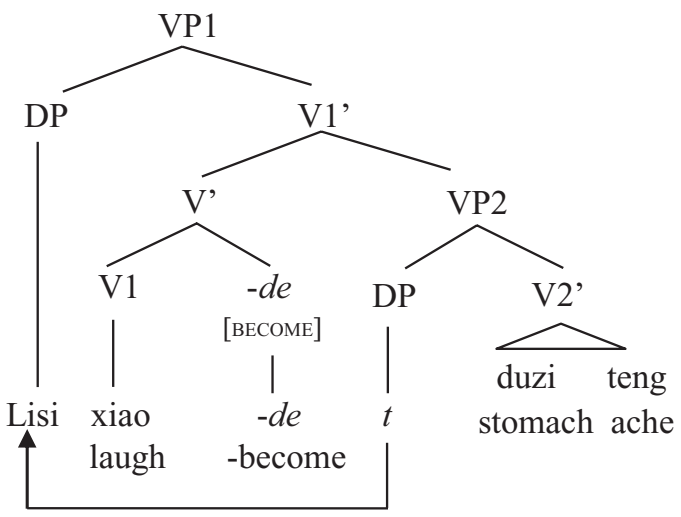

'Lisi got to the state of having stomach ache from laughing.'

(Huang 2006:24 [63]) 
$(51)$

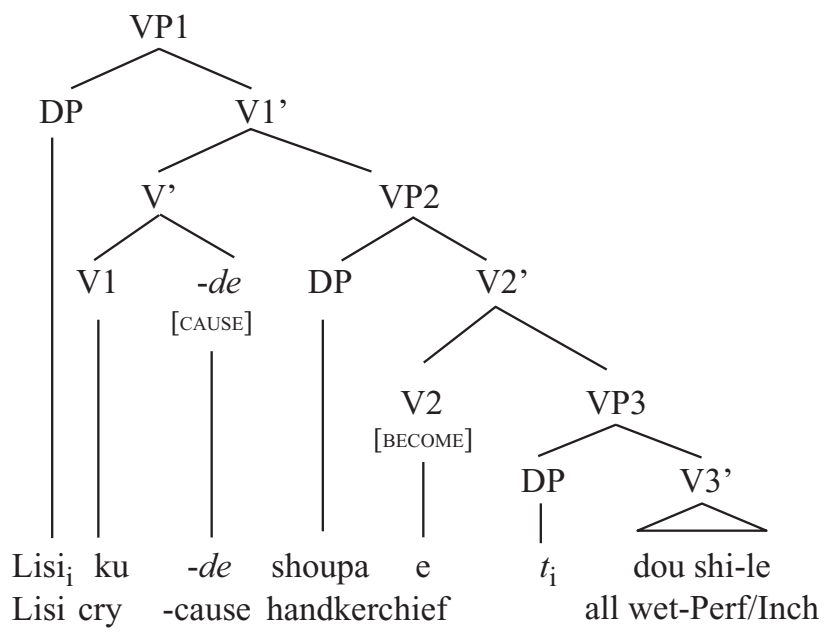

'Lisi cried the handkerchief wet.'

(Huang 2006: 25 [70])

As to how the manner $\mathrm{V}$ is merged with $-d e$, Huang (2006: 38-39, fn. 19) lists two possibilities but does not specify the detail. It is noted, however, by Huang (2015: 24-25) that the operation "may be delayed to PF component" to satisfy the phonological defectiveness of $-d e$. Based on the restriction of manner adverbial modification, Wang (2014) proposes, following Huang $(2006,2015)$ and the late insertion hypothesis in DM, that the verbs in Chinese resultative and descriptive V-de constructions can be achieved at MS after the syntax has completed its operations. In this line, a resultative V-de sentence, such as in (52), is analyzed as (53), where xiao 'laugh' is externally merged with -de at MS, which is shaded in gray to mark it as a postsyntactic morphological operation.

(52) Lisi xiao de duzi teng.

Lisi laugh DE stomach ache

'Lisi got stomach ache from laughing.'

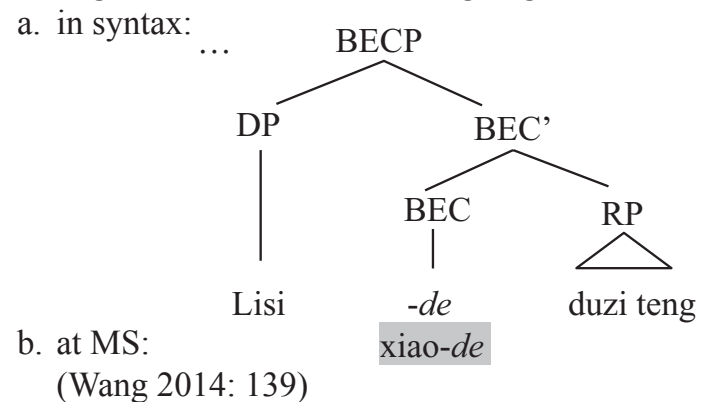

This adjunct analysis has been extended to the analyses of other constructions in Chinese, as argued by Wang and Chin (2016, 2018). For instance, Wang and Chin (2016) assume that the verbs in flip-flop constructions are not generated in syntax but are postsyntactically merged at MS in the phonological level. A covert 
light verb $\emptyset_{\text {HOLD }}$ is assumed to be available in a flip-flop sentence. To meet the phonological requirement of $\emptyset_{\text {HOLD }}$, a manner-denoting verb (cf., Huang 2006) is externally merged with $\emptyset_{\text {HOLD }}$ at MS, as depicted in (54).

(54) a. in syntax:

b. after syntax:

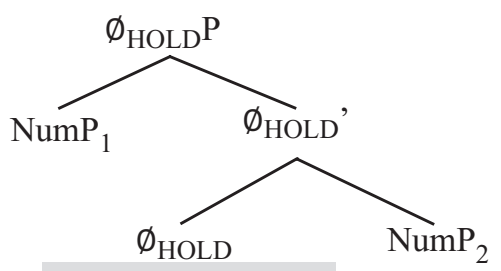

(Wang and Chin 2016: 52)

One key advantage of adopting such a morphosyntactic analysis is that the restriction of manner adverbial modification observed in some Chinese constructions can be explained easily. The reason is simple. In line with Travis (1988), adverbs are licensed by a feature in the head and the manner adverbial should get licensed by a head such as V. Or the manner adverbial is licensed by $V^{\prime}$ ' in the sense of Huang 1982; Tang 1990, Tang 2001; Huang et al. 2009. Since the $\mathrm{V}$ is not introduced into the derivation in syntax, there is no $\mathrm{V} / \mathrm{V}$ ' to license the manner adverbial. Hence, the restriction of manner adverbial modification receives a natural explanation. ${ }^{6}$ Due to similar restrictions on action verbs, such a morphosyntactic approach can be extended to PSC, as detailed below.

6 An anonymous reviewer kindly reminds us of the existence of a light verb, which is also a verbal head and should be able to license a manner adverbial as well. This possibility, however, is difficult to achieve for a light verb as BEC. We assume that a light verb BEC is not suitable for licensing manner adverbials, mainly due to semantic reasons. A relevant discussion in the literature is that manner adverbs can modify dynamic predicates but seldom modify stative predicates. It has been claimed (for example, in Maienborn 2005 and Katz 2008) that manner adverbials are systematically excluded on semantic grounds, as in (i) (See Ernst 2016 for some possible exceptions).

(i) a. *John resembled Sue slowly.

b. *She desired a raise enthusiastically.

c. *They hate us revoltingly. (Katz 2008: 221 [5a-c])

Similar to stative predicates, BEC is a functional head and it itself cannot be modified by a manner adverb. It is hard to test this with a covert light verb. However, we can test it with the overt form of BEC, i.e., biande (Huang 2006), which is difficult to be modified by a manner such as manmande 'slowly', as in (ii). The possible reading of manmande in (ii) is gradually, not slowly. Though a light verb is not fully equivalent to its lexical counterpart (cf., Lin 2001; Huang 2006; Feng and Shi 2018: 314, fn. 25), we still believe similar manner restriction can apply to a covert light verb BEC.

(ii) Ta manmande biande piaoliang le. she gradually become pretty LE

a. \#'She turns pretty slowly.'

b. 'She turns pretty gradually.' 


\subsection{A morphosyntactic analysis to PSC}

Based on the above discussion, PSC are argued to be formed at the interface between syntax and morphology. For instance, (18a) can be depicted as in (55), where the operations at PF (i.e., EMM and (phonological) head movement) are shown with shaded gray.

a. in syntax: ...

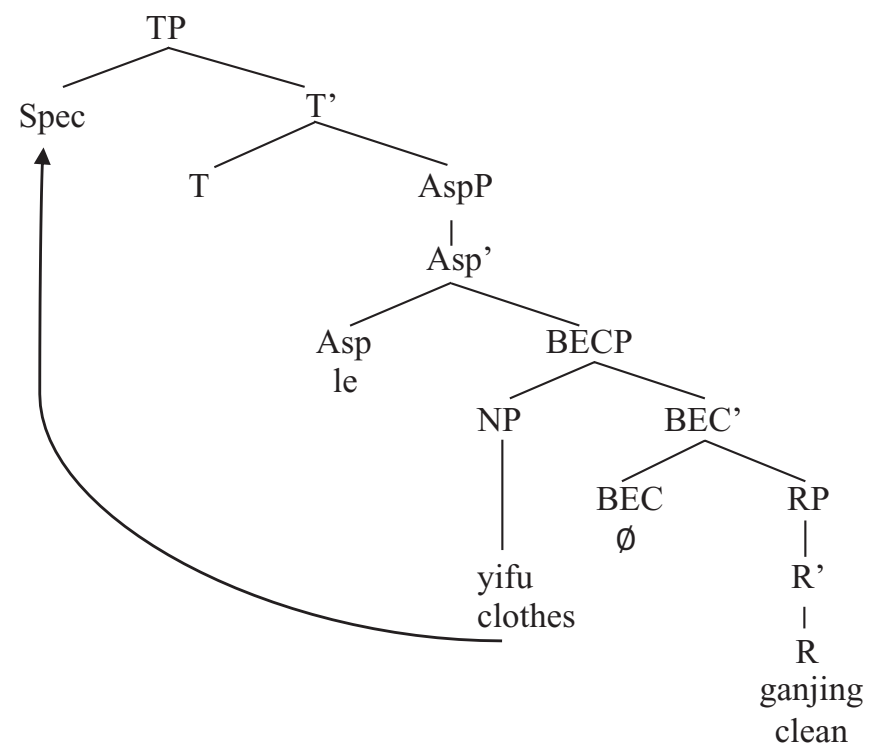

b. after syntax:

b1: PF Head Movement I: R head-moves to $\emptyset_{\mathrm{BEC}}$, forming "clean- $\emptyset_{\mathrm{BEC}}$ "

b2: External Morphological Merger (EMM):

$\mathrm{V}_{<M A N N E R>}$ externally merges with $\mathrm{R}-\emptyset_{\mathrm{BEC}}$, forming "Wash ${ }_{\angle M A N N E R>}$-clean- $\emptyset_{\mathrm{BEC}}$ "

b3: PF Head Movement II:

$\mathrm{V}_{\angle M A N N E R>}-\mathrm{R}-\emptyset_{\mathrm{BEC}}$ head-moves to Asp, forming "wash ${ }_{\angle M A N N E R>}-$ clean- $\emptyset_{\mathrm{BEC}}-l e$ "

Under the spirit of DM, the derivation of PSC is formed at two levels: in syntax and after syntax. As depicted in (55a), in syntax, PSC mainly consist of a BECOME Phrase (BECP), which selects an NP as a specifier and a resultative phrase (RP) as a complement. Meanwhile, BECP is selected by Asp le as its complement (cf., Embick 2004). Following Dong (2015), Yang and Cheng (2018), and Pan (2019a), we assume $l e$ is heading the AspP. ${ }^{7}$ To satisfy the extended projection principle

7 An anonymous reviewer questions how to derive a sentence as in (ia, b). The intrinsic meaning of these two sentences is about whether it is (im)possible for the dirty clothes to be washed clean and it is mainly determined by the dirtiness of the clothes and a human agent is not a must.

(i) a. Yifu xi de ganjing le. clothes wash DE clean LE

'The clothes can be washed clean.' 
(EPP) (Chomsky 1981), the NP in BECP moves to the Spec of a tense phrase (TP) in syntax. The light verb $\emptyset_{\mathrm{BEC}}$ is something similar to an affix, which is required to attach to a host (Marantz 1984). Due to the affixal property of $\emptyset_{\mathrm{BEC}}$, $\mathrm{R}$ head-moves to $\emptyset_{\mathrm{BEC}}$, as shown in (55b1). Then, the manner-denoting verb wash merges with R- $\emptyset_{\mathrm{BEC}}$ as a root with the verbal category, as shown in (55b2). Finally, to satisfy the affixal property of le, $\mathrm{V}_{<M A N N E R>}-\mathrm{R}-\phi_{\mathrm{BEC}}$ head-moves to le, forming wash $_{<M A N N E R>}$-clean- $\emptyset_{\mathrm{BEC}}$-le, as shown in (55b3). Here, we follow Chomsky (1995: 368), Boeckx and Stjepanović (2001: 351-352), and Chomsky et al. (2019) to assume that head movement is not a narrow syntactic phenomenon, but a PF phenomenon, which takes place after Spell-Out. Meanwhile, we adopt Embick and Noyer's (2001) assumption that PF takes the output of syntax and applies movement operation to satisfy the morphophonological dependency. In this line, the head movement shown in (55b) is not syntactically driven but triggered for some morphological reasons. ${ }^{8}$ Suppose the verb, as a root, merges with R- $\emptyset_{\mathrm{BEC}}$ in syntax, as often proposed in literature (i.e., Embick 2004), the restrictions on manner adverbials discussed in Section 3 will be left unexplained. Given this, the verbs in PSC, acting as adjuncts, should be merged postsyntactically. This is in the same spirit with Harley (2005: 61, fn. 8), Huang (2015), Wang (2014), and Wang and Chin (2016, 2018), in which verbs are postsyntactically merged with light verbs at the PF.

The bare verb assumed here is relatively richer than a naked root as traditionally assumed in DM, as it contains a verbal category feature. In the naked roots view, roots are category-neutral and contain no syntactically relevant

$\begin{array}{llll}\text { b. Yifu xi bu ganjing le. } \\ \text { clothes wash not clean } & \text { LE } \\ \text { 'The clothes cannot be washed clean.' }\end{array}$

As pointed out by the reviewer, (ia, b) should be typed as PSC. They are PSC with a potential modal like de/bu (Tsai 2001; Wu 2004; Wang 2017; and so on) We may follow Wang (2017) to assume that $d e$ and bude (allomorph of $b u$ in $\mathrm{V}-b u-\mathrm{R}$ ) are two functional heads with potential meaning, which head a ModalP that is sandwiched between BECP and AspP. The PF movement will cross at $d e / b u d e$ and finally land at le. As assumed by Wang (2017), a morphological merger takes place between $d e / b u(d e)$ and $\mathrm{VR}$, deriving the right word order.

8 An anonymous reviewer notes that DM assumes head movement in narrow syntax, which is necessary for various theory-internal reasons. It is therefore a bit strange to adopt a PF-driven head movement with the DM framework. Yes, it is often proposed in the literature that head movement (HM) operates in syntax in DM. The PF movement in DM normally refers to Lowering and Left Dislocation (i.e., Embick and Noyer 2001, Embick and Noyer 2007). But due to the late Insertion of DM, the syntactic head movement must be achieved morphologically at PF (cf., Matushansky 2006). As there are no semantic effects involved in head movement and head movement violates principles of minimal computation, Chomsky $(1995,2001)$ and Boeckx and Stjepanović $(2001$ : 351-352) assume that head movement takes place at PF in Minimalist Program. This issue is still at debate, as Chomsky et al. (2019: 250) point out that "at least some instances of HM might fall within the mapping to PHON (phonetic representation)". From this perspective, we assume that head movement takes place at PF, as proposed by Acedo-Matellán (2016: 61-62) and Mare (2018). 
information, as exemplified with a completely bare root $\sqrt{ } \mathrm{CAT}$, which is selected by a functional head $n$ to derive the noun cat (Embick and Noyer 2001; Embick 2015; and so on). For instance, Hu's (2019) DM analysis of middle constructions in Chinese follows this tradition, in which a bare root with no category is merged with $\emptyset_{\mathrm{BEC}}$ in syntax, as either a complement or adjunct. Adopting such an analysis into PSC awaits the explanation regarding why the inserted root is actually verblike, but not noun-like (cf., Embick 2004: 370-371; Alexiadou et al. 2014: 4; Borer 2013). Meanwhile, the restriction of manner adverbial modification is also a problem to be tackled with.

As a matter of fact, the exact status of the root is at issue in literature (Halle and Marantz 1993; Embick 2000; Lin 2004; Ramchand 2008; Huang et al. 2009; Borer 2013; Haugen and Siddiqi 2013; Alexiadou et al. 2014; Harley 2014; De Belder and van Craenenbroeck 2015; Hu 2018; Irwin 2019). As pointed out by Ramchand (2008: 11), the roots "may contain some syntactic information, ranging from category information to syntactic selectional information and degrees of argument-structure information, depending on the particular theory". The bare verbal root proposed here is much poorer than a well-dressed root as it bears no argument information. The merger of a verbal root is to enrich the semantic content of a light verb (cf., Pensalfini 1997: 138-139; Harley 2005: 61-62). It is driven by morphology while introducing some limited new semantic information (cf., Richards 2016; Martinović 2019).

\subsection{Further elaborations on the morphosyntactic analysis}

\subsubsection{The selection of $\mathrm{V}$}

This section elaborates the above-mentioned morphosyntactic analysis of PSC. Inspired by Huang (2006), PSC such as (56a)(=[18a]) can be paraphrased with bian 'become', which is equivalent to the light verb BEC, as shown in (56b). Similarly, (57a) means that the clothes become torn through tearing. (57b) means that table becomes clean via wiping. (57c) denotes that the meal has become ready via cooking. (57d) means that the room has got tidy via cleaning.
a. Yifu xi ganjing le. clothes wash clean LE 'The clothes have got clean from washing.'
b. Yifu (tongguo) xi (bian) ganjing le. clothes by wash BECOME clean LE 'The clothes have got clean from washing.'

(57) a. Yifu si po le. clothes tear torn LE 'The clothes have got torn from tearing.'

b. Zhuozi ca ganjing le. table wipe clean LE 'The table has been got clean from wiping.' 

c. Fan zhu hao le.
meal cook finished LE
'The meal has got ready from cooking.'
d. Fangjian shoushi wan le.
room organize finished LE
'The room has got ready from cleaning.'

Though the verb, as an adjunct, is assumed to merge with R- $\emptyset_{\mathrm{BEC}}$ at PF in PSC, it does not mean that any verb can do this. The selection of the verb is not arbitrary but constrained semantically and/or pragmatically (cf., Huang 2006; Wang 2014; Wang and Chin 2018; Irwin 2019). In interpreting a given morphosyntactic representation $\mathrm{R}-\emptyset_{\mathrm{BEC}}$, only verbs that can denote the manners of $\mathrm{R}-\emptyset_{\mathrm{BEC}}$ may serve as the roots for $\mathrm{R}-\emptyset_{\mathrm{BEC}}$. For instance, shi 'be', a typical stative verb, cannot be merged with R- $\emptyset_{\mathrm{BEC}}$ to denote the manner, as shown in (58). This may be due to the semantic incompatibility between the stative verb $b e$ and $\emptyset_{\mathrm{BEC}}$, as $\emptyset_{\mathrm{BEC}}$ denotes the change of state.

$$
\begin{aligned}
& \text { *Yifu shi ganjing le. } \\
& \text { clothes be clean LE } \\
& \text { *'The clothes became clean through being.' }
\end{aligned}
$$

Meanwhile, the postsyntactically merged verbs in PSC need to match with the patient-subject NPs and Rs. For instance, verbs such as $x i$ 'wash', ca 'wipe', or cuo 'rub' are found to be quite natural in (59), in which the subject is yifu 'clothes'; however, other verbs such as $d a$ 'hit' or $t i$ 'kick' are inappropriate, as in (60). If, however, the resultative ganing 'clean' in (59) is changed as gan 'dry', as in (61), the sentences become less unacceptable. In this context, the verb should be ning 'twist', shai 'put in sun', or shuai 'swing', as in (62), since yifu 'clothes' normally become gan 'dry' through these actions, rather than by the actions mentioned in (61). This may be due to the simple fact that the verb, as a manner adjunct, is applied to describe how the patient-subject undergoes the change. If the manner is improper, it is barred from merging with $\mathrm{R}-\emptyset_{\mathrm{BEC}}$ due to semantic and/or pragmatic constraints.

(59) Yifu xi/ca/cuo ganjing le.

clothes wash/wipe/rub clean LE

'The clothes have turned clean from washing/wiping/rubbing.'

(60) \#Yifu da/ti ganjing le.

clothes hit/kick clean LE

Intended: 'The clothes have turned clean from hitting/kicking.'

(61) \#Yifu xi/ca/cuo gan le.

clothes wash/wipe/rub dry LE

Intended: 'The clothes have turned dry through the washing/wiping/rubbing.'

(62) Yifu ning/shai/shuai gan le.

clothes twist/put.in.sun/swing dry LE

'The clothes have become dry through twisting/putting in sun/swinging.' 


\subsubsection{Le as an aspect head}

This subsection aims to discuss the syntactic role of le in PSC. As reviewed in Section 2.4, the le in PSC is obligatory; otherwise, PSC may become ungrammatical or change into an imperative sentence, as respectively shown in $(18 b, c)$. Due to the obligatoriness, we follow Dong (2015), Yang and Cheng (2018), Paul (2014), and Pan (2019b: 16-17) to consider le in PSC as an inflectional aspect marker, which is selected by $\mathrm{T}$ as its complement in syntax. ${ }^{9}$

One looming empirical problem for this aspect analysis of le is that le can sometimes co-occur with guo, as pointed out by both reviewers. If guo in (63) is also an experiential aspect marker, it would bring a problem as the aspect marker $l e$ and guo cannot co-occur (i.e., Li and Thompson 1981: 204).
a. Yifu yijing xi guo le. clothes already wash GUO LE 'Clothes has been ready from washing.'
b. Diannao yijing xiu guo le, computer already repair GUO LE buguo wo bu queding neng bu neng yong. but I not sure can not can use

'The computer has been repaired. But I am not sure whether it is ready for use.'

On closer scrutiny, the guo-le co-occurrence is not a problem for us, as the guo in (63) could be another use of guo, which is often noted as guo in literature, which denotes wanjie 'the end' of an action, as noted by Chao (1968), Lü (1999: 246247), and Kong (1986). This usage is distinct from the experiential aspect marker guo, which is often glossed as guo in literature. It is widely accepted that $g u o_{1}$ can occur with $l e_{1} / l e_{2} / l e_{1}+l e_{2}$ (Chao 1968; Lü 1999; Kong 1986: 273). Meanwhile, Lü (1999: 246) notes that V + guo is VR-equivalent, and Liu (1988: 13) notes that VR normally cannot co-occur with guo, as shown in (64). This might be due to the fact that both wan and guo refer to results and there is a semantic redundancy involved when the two co-occur (cf., Tang 2006: 6).

*Yifu xi wan guo le.
clothes wash finish GUO LE
Intended: 'Clothes have been ready from washing.'

As noted by an anonymous reviewer, however, there are indeed occasions in which guo and ganjing can co-occur, as shown in (65). We agree that the guo in (65) is not $g u o_{1}$, but a real experiential marker $g u o_{2}$. However, this sentence

9 As discussed in Section 3.3, we cannot deny the possibility that the le in PSC may be a conglomeration of the perfective aspect $l e_{1}$ and sentence-final particle $l e_{2}$. Suppose $l e_{2}$ is there, it could be either that $l e_{2}$ is head-initial and the whole TP moves leftward (cf., Kayne 1994) or $l e_{2}$ is head-final and basegenerated there (Paul 2014; Erlewine 2017; Pan 2017, Pan 2019b). We leave these two possibilities open. 
should not be typed as PSC. ${ }^{10}$ In line with Li (1987) and Wang and Chin (2018), (65) can be analyzed as (66), in which [Zhe jian yifu xi ganjing guo] acts as a sentential subject and it is predicated by [haoji ci] directly or by a covert light verb (i.e., you 'HAVE'). From our perspective, this sentential subject should not be an instance of PSC. A support for this comes from manner adverbial modification, which has been shown to be impossible in PSC. However, a manner adverbial such as yong xiangzao 'use soap' can be inserted into (65), as shown in (67). In this line, the adjacency between $l e$ and guo is just an illusion and the two are located in two clauses. The $l e$ in (65) should not be analyzed as an aspect marker $l e_{1}$, but something similar to a sentence-final particle $l e_{2}$ (Chao 1968; Li and Thompson 1981).

$\begin{array}{llllllll}\text { Zhe jian } & \text { yifu } & \text { xi } & \text { ganjing } & \text { guo } & \text { haoji } & \text { ci } & \text { le. } \\ \text { this } & \text { CL } & \text { clothes } & \text { wash } & \text { clean } & \text { GUO } & \text { several time } & \text { LE }\end{array}$
'The clothes have been washed clean for several times.'

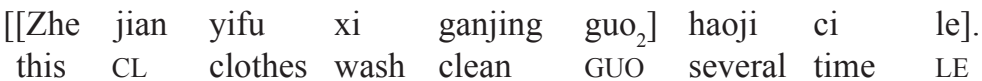

'The clothes have been washed clean for several times.'

(67) Zhe jian yifu yong xiangzao xi ganjing guo haoji ci le. this CL clothes use soap wash clean GUO several time LE 'The clothes have been washed clean with soaps for several times by me.'

In this line, we can explain some seeming le-related counterexamples provided by both reviewers, as shown in $(68 \mathrm{a}, \mathrm{b}, \mathrm{c})$, in which le does not immediately follow $\mathrm{R}$ or guo, but after DurP or a frequency phrase (FrP). As noted by both reviewers, the $l e$ in these sentences has some special properties that the aspect le does not have, which casts doubts on our aspect analysis of le in PSC. We here follow a reviewer's suggestion to consider the possibility that the le in (68) is actually not a perfective aspect marker, and therefore, they are not real counterexamples to our aspectual analysis of $l e$ in PSC. Adopting the analysis of (65), as informally shown in (66), we assume that [yifu xi hao] in (68a) and [xifu xi guo] in (68b) are sentential subjects and they are respectively predicated with DurP and FrP, as illustrated in (69a, b). Distinct from $(68 \mathrm{a}, \mathrm{b})$, yifu 'clothes' in (68c) is prone to be analyzed as a Topic and a covert Agent $\emptyset_{\text {Agent }}$ may be involved (Gong 1980: 341-342), as shown

10 According to Lü (1999: 357-358), PSC can normally be followed by meiyou 'not', as in (i), in which le is optional. The addition of meiyou in (65) renders it unacceptable, which also suggests that (65) is not an instance of PSC.

(i) Yifu xi ganjing (le) meiyou?
clothes wash clean LE not
'Have the clothes turn clean from washing?'

(ii) *Zhe jian yifu xi ganjing guo haoji ci (le) meiyou? this CL clothes wash clean GUO several time LE not 'Have the clothes been washed clean for several times?' 
in (70). ${ }^{11}$ If these analyses are on the right track, $(68 \mathrm{a}, \mathrm{b}, \mathrm{c})$ should not be typed as PSC and they are not real counterexamples to our analysis.
a. Yifu xi hao san tian le. clothes wash finished three days LE 'It has been three days since the clothes have been washed well.'

b. Yifu xi guo henduo ci le. clothes wash GUO many times LE 'The clothes have been washed for many times.'
c. Yifu xi ganjing (le) wu jian le.
clothes wash clean LE five piece LE

'As to clothes, five pieces of them have been washed.'

$\begin{array}{clllll}\text { (69) a. [[yifu } & \text { xi } & \text { hao }] & \text { san } & \text { tian } & \text { le }] \\ \text { clothes } & \text { wash } & \text { finished three } & \text { day } & \text { LE } \\ \text { b. [[yifu } & \text { xi } & \text { guo }] & \text { henduo } & \text { ci } & \text { le] } \\ \text { clothes } & \text { wash } & \text { GUO many } & \text { time } & \text { LE }\end{array}$

$\begin{array}{llllrlll}\text { (70) } \begin{array}{l}{[\text { Yifu }]} \\ \text { clothes }\end{array} & {\left[\emptyset_{\text {Agent }}\right.} & \text { xi } & \text { ganjing } & \text { (le) } & \text { wu } & \text { jian } & \text { le }] . \\ & \text { wash } & \text { clean } & \text { LE } & \text { five } & \text { piece } & \text { LE }\end{array}$

\subsection{Derivation of two elided forms of PSC}

As discussed in Section 1.1, sentences like (5b) are not the only form of PSC. There are two special variants of PSC: one is " $\mathrm{NP}_{\text {Patient }}+\mathrm{R}+l e$ ", as in (71); the other is " $\mathrm{NP}_{\text {Patient }}+\mathrm{V}+l e$ ", as in (13), repeated as (72). However, as pointed out by an anonymous reviewer, these two types of elided sentences cannot be naturally used unless under certain specific contexts (Ma 1987). Comparatively speaking, (71) needs more contexts than (72). Suppose they are acceptable under certain contexts, a follow-up question is how to derive them.

(71) ?Yifu ganjing le.

clothes clean LE

'The clothes have turned clean.'

(72) Yifu xi le.

clothes wash LE

'The clothes have undergone the process of washing.'

From the semantic perspective, (71) is roughly equivalent to (73), in which an overt bian is available. Similarly, we can assume that (71) contains a light verb $\emptyset_{\mathrm{BEC}}$, which selects RP as its complement. In this line, PSC such as (71) can be derived as in (74). The syntactic level of (74a) is the same as the one in (55a). The only difference between (55) and (74) lies in the postsyntactic operations.

11 Adopting a broad definition, Gong (1980: 336) and Zhan (1992: 202) take a sentence such as (68c) as PSC. 
No external merge of a root verb is introduced in (74b) at MS. There are only PF head movements operated after syntax, as shown in $(74 \mathrm{bl}, \mathrm{b} 2)$.

The existence of (71) shows that the external merge of a verbal root is not obligatory when the semantic and pragmatic information is specified under certain contexts. ${ }^{12}$ This possibility is predicted under a morphological merger perspective. When ganjing moves upward with $\emptyset_{\mathrm{BEC}}$, the affixal property of $\emptyset_{\mathrm{BEC}}$ has been met. The two may move upward directly to satisfy the affixal property of $l e$, without introducing an external root. The overt form of $\mathrm{R}$ can itself help to satisfy the affixal properties of $\emptyset_{\mathrm{BEC}}$. However, when the $\mathrm{R}$ is not taking an overt form, the $\mathrm{V}$ must be present overtly. This is another variation of PSC, which takes the form "NP $+\mathrm{V}+l e "$, as exemplified in (72).

(73) Yifu bian ganjing le. clothes become clean LE 'The clothes became clean.'

(74) a. in syntax

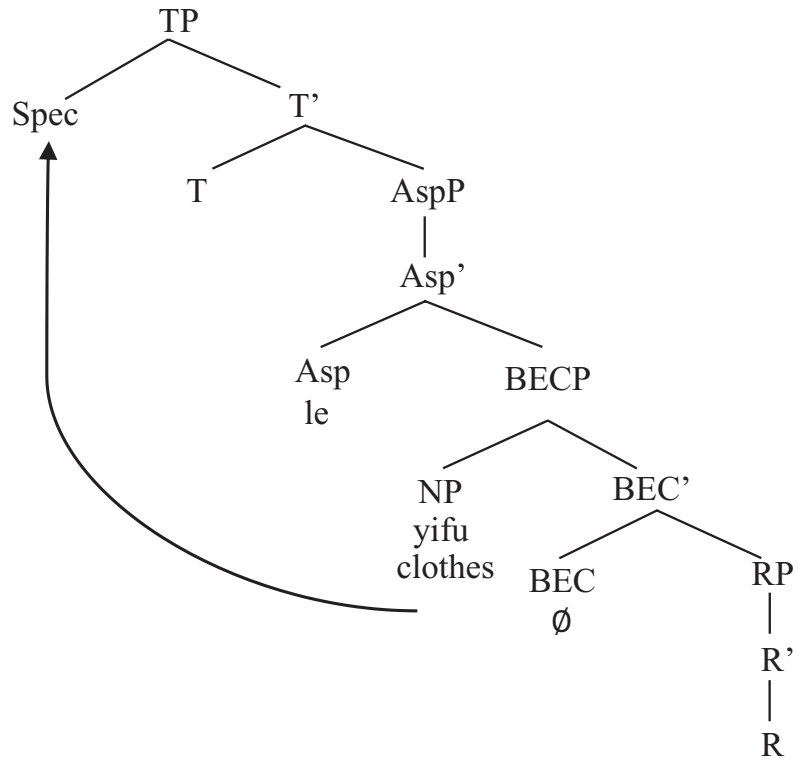

ganjing clean

b. after syntax:

b1: PF Head Movement I: R head-moves to $\emptyset_{\mathrm{BEC}}$, forming "clean- $\emptyset_{\mathrm{BEC}}$ "

b2: PF Head Movement II: R- $\emptyset_{\mathrm{BEC}}$ head-moves to Asp, forming "ganjing$\emptyset_{\mathrm{BEC}}-l e "$

12 If the verb root is not introduced, the manner of the change of state is not specified, which therefore requires the context to supply further information. 
Based on the analysis of the "NP$P_{\text {Patient }}+\mathrm{V}+\mathrm{R}+l e$ " structure, (72) can be depicted as in (75), where $\mathrm{R}$ is empty at the phonological level but available in syntax. According to the semantic interpretation of PSC and the inchoative template of BEC (Huang 2006), there must be an implicit R in syntax to express the result of state change. To be specific, although (72) does not overtly refer to a result, it may semantically indicate a general result as hao/wan 'finished' or an expected specific result such as ganjing 'clean' (cf., Chao 1968: 246), as in (76a, b). Thus, for the elided " $\mathrm{NP}_{\text {Patient }}+\mathrm{V}+l e$ " (i.e., [72]), the syntactic structure is the same as normal PSC, as shown in (55a) and (75a). The only difference between (55) and (72) lies in the postsyntactic operations, as shown in (75b). After syntax has completed its operations, $\emptyset_{\mathrm{R}}$ head-moves to $\emptyset_{\mathrm{BEC}}$, hoping to satisfy the affixal property of $\emptyset_{\mathrm{BEC}}$. However, since both R and BEC are empty at the phonological level, an overt form of $\mathrm{V}$ must be externally merged with $\emptyset_{\mathrm{R}}-\emptyset_{\mathrm{BEC}}$ to meet their affixal properties. After that, V- $\emptyset_{\mathrm{R}}-\emptyset_{\mathrm{BEC}}$ head-moves to the Asp le to meet the morphological requirement of $l e$, as illustrated in (75b). If there is no $\mathrm{V}$ introduced into the derivation, the morphological properties of these affix-like elements are not met and the sentences would be ill-formed, as shown in (77).

(75) a. in syntax

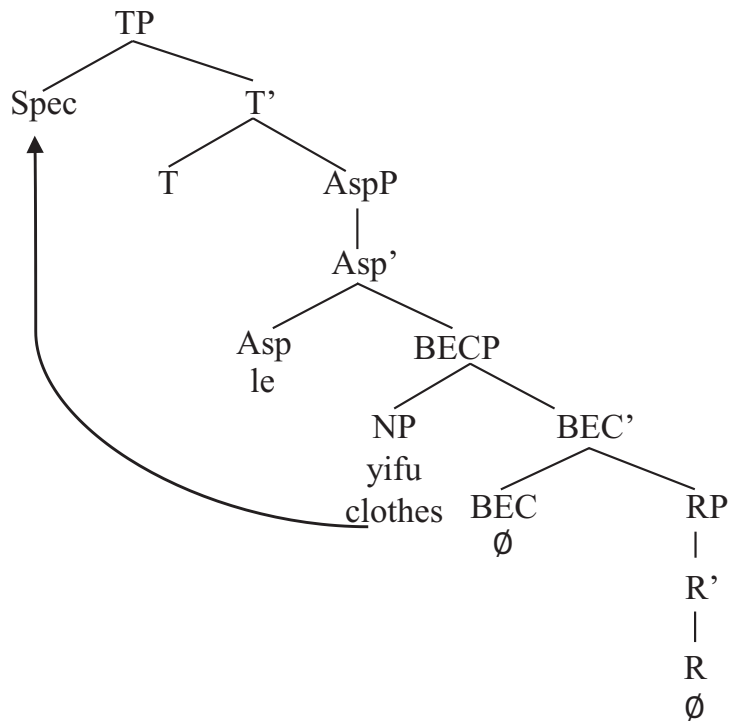

b. after syntax:

b1: PF Head Movement I: $\emptyset_{\mathrm{R}}$ head-moves to $\emptyset_{\mathrm{BEC}}$, forming “ $\emptyset_{\mathrm{R}}-\emptyset_{\mathrm{BEC}}$ "

b2: External Morphological Merger (EMM):

$\mathrm{V}_{<M A N N E R>}$ externally merges with $\emptyset_{\mathrm{R}}-\emptyset_{\mathrm{BEC}}$, forming " $\mathrm{xi}_{\angle M A N N E R>}-\emptyset_{\mathrm{R}}-\emptyset_{\mathrm{BEC}}$ " b3: PF Head Movement II:

$\mathrm{V}_{<M A N N E R>}-\emptyset_{\mathrm{R}}-\emptyset_{\mathrm{BEC}}$ head-moves to Asp, forming " $\mathrm{xi}_{\angle M A N N E R>}-\emptyset_{\mathrm{R}}-\emptyset_{\mathrm{BEC}}-l e$ " 
a. Yifu xi (hao/wan) le.

clothes wash finished LE

'The clothes have got ready (from washing).

b. Yifu xi (ganjing) le.

clothes wash clean LE

'The clothes have got clean (from washing).'

(77) *Yifu le.

clothes LE

To sum up, the two elided forms of PSC share the same underlying syntactic structure with normal PSC. They differ in the postsyntactic morphological operations at $\mathrm{MS} / \mathrm{PF}$.

\subsection{A revisit to some puzzles in PSC}

As shown above, the current morphosyntactic analysis of PSC can help to explain the observed puzzles.

First, this analysis can explain the restriction of manner adverbial modification and the nonavailability of manner zenme 'how'. Being distinct from a normal action verb, the verb in PSC, as a bare root, is not introduced into the derivation until at $\mathrm{MS} / \mathrm{PF}$, which takes place after syntax has completed its operations. Since V is not available in syntax, there is no way to license the manner adverbial (reading).

Meanwhile, this approach can explain why the verbs in PSC can be either transitive or ditransitive, without violating the theta-criterion (Chomsky 1981). The theta-criterion demands that each argument bears one and only one theta-role, and each theta-role is assigned to one and only one argument. However, though there is only one patient in PSC and the agent is either unavailable or suppressed (cf., Dong 2015: 310; Yang and Cheng 2018), the verbs in PSC are transitive or ditransitive. This seeming violation of the theta-criterion can be explained easily with the root analysis of the verbs in PSC (cf., Wang 2014; Wang and Chin 2016, Wang and Chin 2018; and so on). This root, which has only a verbal category (cf., Ramchand 2008), does not take arguments (cf., Marantz 1984: 255-258; Embick 2000). Therefore, the (di)transitivity of verbs in PSC will not violate the thetacriterion even if the agent is unavailable.

Moreover, the bare root assumption avoids the potential problems involved in the syntactic/semantic approach (e.g., Agent suppression, motivations of movement) (i.e., Cheng 1989; Cheng and Huang 1994; Pan and Han 2005; Ting 2006; Yang and Cheng 2018; Hu 2019). In our analysis, the patient is a base-generated subject (cf., Cheng and Huang 1994; Ting 2006), which is base-generated at [Spec, BECP] and moves to [Spec, TP] to satisfy EPP. Thus, unlike the movement hypothesis, there is no need to find corresponding agent-subject sentences of PSC. The PSC that do not have corresponding agent-subject counterparts, as shown in (7a), can be explained accordingly. Meanwhile, following Zhan (1992: 197-198), we distinguish 
agent-subject sentences such as (7b) from PSC (contra Gong 1980: 341-342; Rong 2006; Dong 2015: 310-311), as they can be modified by an agent-oriented adverb or manner adverbial, as shown in (78), while real PSC cannot. Distinct from the structure of PSC, the shu 'book' in (78) can be taken as a sentence-initial topic that moves from a postverbal object position (cf., Huang et al. 2009). ${ }^{13}$

(78) Shu ta qiaoqiaode/ yibenyibende mai wan le.

book he secretly/one.by.one sell done LE

'The books were sold by him secretly/one by one.'

So far, we have shown that the seeming action verb V in PSC is not a real action verb with argument structure, but a verbal root merged at MS/PF. Though this analysis successfully explains some verb-related puzzles, a theoretical problem arises simultaneously: if the external merger of the verb operates at PF, the newly introduced meaning of the verb may not get Full Interpretation, as it does not get into LF (Chomsky 1995). Whether there is a direct involvement of morphophonological factors in the syntactic computation (i.e., Richards 2016; Martinović 2019) is still open and awaits further research, as pointed out by Chomsky et al. (2019: 252). There are two possible solutions. One is carried out under the framework of the Y-model (Chomsky 1981, Chomsky 1995). That is to assume that the externally merged verb at MS is base-generated as a root with no thematic information in the lexicon and is not introduced into the derivation until MS/PF (cf., James Huang, personal communication; Wang 2014: 208; Pan 2019a). The other solution is to revise the Y-model. In line with Trotzke (2015), Wang and Chin (2018) postulate that PF and LF may be communicable in some special cases. Hence, the meaning of the inserted verb at PF can get into LF and be fully interpreted. This question is still open for DM. Further research needs to be done on this issue.

\section{Conclusion}

In this article, we have analyzed the restrictions on the verbs of PSC and explored the internal structure of PSC from the morphosyntactic perspective. Under the framework of DM, PSC are derived at the interface between syntax and morphology. In syntax, PSC consist of a BECP, which selects an NP as a specifier, and an RP as a complement. Above the BECP, there is an AspP headed by le. To satisfy the EPP, the NP in BECP moves to the [Spec, TP] position. After syntax, R head-moves to $\emptyset_{\mathrm{BEC}}$ at PF to satisfy the phonological requirement of $\emptyset_{\mathrm{BEC}}$, forming $\mathrm{R}-\emptyset_{\mathrm{BEC}}$; then, a bare verbal root merges with $\mathrm{R}-\emptyset_{\mathrm{BEC}}$ at PF to denote the manner of the change of state. Furthermore, due to the phonological requirement of le, $\mathrm{V}-\mathrm{R}-\emptyset_{\mathrm{BEC}}$ head-moves to Asp le, producing the derived form. The elided forms of PSC can be derived similarly, being slightly different in morphological operations. This research, if it is on the right track, shows that covert light verbs and morphology may play an interactive role in the derivation of some typical constructions in Chinese.

13 Similar tests have been made between middle sentences and fake middle sentences with an agent in the paper by $\mathrm{Hu}(2018: 97-98)$. 


\section{Acknowledgments}

This research was inspired by Professor C.-T. James Huang's (2006) original research on phrasal resultatives in Chinese. We are grateful to two anonymous reviewers for their stimulating challenges and comments on an early draft, which substantially improved the quality of this paper. Meanwhile, we would like to thank Wei Chin, Dun Deng, Chengru Dong, and Daran Yang for relevant discussion during the revision. This research was partially supported by the National Social Science Fund of China (17BYY157).

\section{References}

Acedo-Matellán, Víctor. 2016. The morphosyntax of transitions: A case study in Latin and other languages. Oxford: Oxford University Press.

Ackema, Peter \& Maaike Schoorlemmer. 1994. The middle construction and the syntax-semantics interface. Lingua 93(1). 59-90.

Ackema, Peter \& Maaike Schoorlemmer. 2017. Middles. In Martin Everaert \& Henk C. van Riemsdijk (eds.), The Wiley Blackwell companion to syntax, 2nd edn, 2499-2573. Hoboken, NJ: John Wiley \& Sons, Inc.

Alexiadou, Artemis, Hagit Borer \& Florian Schäfer (eds.). 2014. The syntax of roots and the roots of syntax. Oxford: Oxford University Press.

Aronoff, Mark. 1994. Morphology by itself: Stems and inflectional classes. Cambridge, MA: MIT Press.

Boeckx, Cedric \& Sandra Stjepanović. 2001. Head-ing toward PF. Linguistic Inquiry 32(2). 345-355.

Borer, Hagit. 2013. Structuring sense. Vol. 3, Taking form. Oxford: Oxford University Press.

Cao, Hong. 2004. Lun zhongdongju de jufa gouzao tedian [On the syntactic features of middle constructions in Chinese]. Shijie Hanyu Jiaoxue [Chinese teaching in the world] 3. 38-48.

Cao, Hong. 2005. Lun zhongdongju de yuyi biaoda tedian [On semantic features of middle constructions in Chinese]. Zhongguo Yuwen [Studies of the Chinese language] 3. 205-213.

Chao, Yuen Ren. 1968. A grammar of spoken Chinese. Berkeley, CA: University of California Press.

Chen, Matthew. 1987. The syntax of Xiamen tone sandhi. Phonology Yearbook 4. 109-150.

Cheng, L.-S. Lisa. 1989. Transitivity alternations in Mandarin Chinese. In Marjorie K. M. Chan \& Thomas Boyden Ernst (eds.), Proceedings of the 3rd Ohio State University Conference on Chinese Linguistics, 81-94. Bloomington, IN: Indiana University Linguistics Club.

Cheng, L.-S. Lisa. 2008. Deconstructing the shi . . de construction. The Linguistic Review 25. 235-266.

Cheng, L.-S. Lisa \& C. T. James Huang. 1994. On the argument structure of resultative compounds. In Matthew Chen \& Ovid Tzeng (eds.), Interdisciplinary studies on language and language change in honor of William S.-Y. Wang, 187-221. Taipei: Pyramid. 
Chomsky, Noam. 1981. Lectures on government and binding: The Pisa lectures. Dordrecht: Foris Publications.

Chomsky, Noam. 1995. The minimalist program. Cambridge, MA: MIT Press.

Chomsky, Noam. 2001. Derivation by Phase. In Michael Kenstowicz (ed.), Ken Hale: A life in language, 1-52. Cambridge, MA: MIT Press.

Chomsky, Noam. 2004. Beyond explanatory adequacy. In Belletti, Adriana (ed.), Structures and beyond, 104-131. Oxford: Oxford University Press.

Chomsky, Noam, Angel J. Gallego \& Dennis Ott. 2019. Generative grammar and the faculty of language: Insights, questions, and challenges. In Fernando Martínez-Gil \& Maria Ohannesian (eds.), Stress and its phonological interactions. [Special issue]. Catalan Journal of Linguistics 18. 229-261.

Cinque, Guglielmo. 1988. On Si constructions and the theory of Arb. Linguistic Inquiry 19(4). 521-581.

De Belder, Marijke \& Jeroen van Craenenbroeck. 2015. How to merge a root. Linguistic Inquiry 46(4). 625-655.

Ding, Shengshu, Shuxiang Lü, Rong Li, Dexuan Sun, Xiechu Guan, Jing Fu, Shengzhang Huang \& Zhiwen Chen. 1961. Xiandai hanyu yufa jianghua [Lecture notes in Chinese grammar]. Beijing: The Commercial Press.

Dong, Xiufang. 2015. Shanggu Hanyu xushi yupian zhong you huati kongzhi de shenglüe moshi [Topic-controlled ellipsis in Ancient Chinese]. Zhongguo Yuwen [Studies of the Chinese language] 4. 306-314.

Dowty, David. 1991. Thematic proto-roles and argument selection. Language 67(3). 547-619.

Embick, David. 2000. Features, syntax, and categories in Latin perfect. Linguistic Inquiry 31(2). 185-230.

Embick, David. 2004. On the structure of resultative participles in English. Linguistic Inquiry 35(3). 355-392.

Embick, David. 2015. The morpheme: A theoretical introduction. Berlin: Mouton de Gruyter.

Embick, David \& Rolf Noyer. 2001. Movement operations after syntax. Linguistic Inquiry 32(4). 555-595.

Embick, David \& Rolf Noyer. 2007. Distributed morphology and the syntax/ morphology interface. In Gillian Ramchand \& Charles Reiss (eds.), The Oxford handbook of linguistic interfaces, 289-324. Oxford: Oxford University Press.

Erlewine, Michael Yoshitaka. 2017. Low sentence-final particles in Mandarin Chinese and the final-over-final constraint. Journal of East Asian Linguistics 26(1). 37-75.

Ernst, Thomas. 2016. Modification of stative predicates. Language 92(2). 237-274.

Fagan, Sarah. 1988. The English middle. Linguistic Inquiry 19. 181-203.

Fagan, Sarah. 2009. The syntax and semantics of middle constructions, 2nd edn. Cambridge: Cambridge University Press.

Fan, Jiyan. 1985. Wuding NP zhuyuju [Sentences with indefinite subjects]. Zhongguo Yuwen [Studies of the Chinese language] 5. 321-328.

Feng, Shengli \& Chunhong Shi. 2018. Lun yuti yufa de jiben yuanli, danwei cengji he yuti xitong [The principles, hierarchical units and register system of register grammar] Shijie Hanyu Jiaoxue [Chinese teaching in the world] 32(3). 302-325. 
Féry, Caroline. 2013. Focus as prosodic alignment. Natural Language and Linguistic Theory 31. 683-734.

Gallego, Ángel. 2014. Roots and phases. In Artemis Alexiadou, Hagit Borer \& Florian Schäfer (eds.), The syntax of roots and the roots of syntax, 192-207. Oxford: Oxford University Press.

Gong, Qianyan. 1980. Xiandai Hanyu li de shoushi zhuyu ju [Patient-subject constructions in modern Chinese]. Zhongguo Yuwen [Studies of the Chinese language] 5. 84-96.

Halle, Morris \& Alec Marantz. 1993. Distributed morphology and the pieces of inflection. In Ken Hale \& Sameul J. Keyser (eds.), The view from Building 20: Essays in linguistics in honor of Sylvain Bromberger, 111-176. Cambridge, MA: MIT Press.

Halle, Morris \& Alec Marantz. 1994. Some key features of distributed morphology. In Adrew Carnie, Heidi Harley \& Tony Bures (eds.), Papers on phonology and morphology, 275-288. MIT Working Papers in Linguistics 21. Cambridge, MA: MIT, MIT Working Papers in Linguistics.

Harley, Heidi. 2005. How do verbs get their names? Denominal verbs, manner incorporation and the ontology of verb roots in English. In Nomi Erteschik-Shir \& Tova Rapoport (eds.), The syntax of aspect: Deriving thematic and aspectual interpretation, 42-64. Oxford: Oxford University Press.

Harley, Heidi 2014. On the identity of roots. Theoretical Linguistics 40. 225-276.

Harley, Heidi \& Rolf Noyer. 1999. State-of-the-article: Distributed morphology. Glot International 4(4). 3-9.

Haugen, Jason D. \& Daniel Siddiqi. 2013. Roots and the derivation. Linguistic Inquiry 44(3). 493-517.

Hoekstra, Teun \& Ian Roberts. 1993. Middle Constructions in Dutch and English. In Eric Reuland \& Werner Abraham (eds.), Knowledge and language. Vol. 2, Lexical and conceptual structure, 183-220. Berlin: Springer.

Hole, Daniel. 2004. Focus and background marking in Mandarin Chinese: System and theory behind cai, jiu, dou and ye. London \& New York: Routledge Curzon, 2004.

$\mathrm{Hu}$, Xuhui. 2018. Encoding events-functional structure and variation. Oxford: Oxford University Press.

$\mathrm{Hu}$, Xuhui. 2019. Kuayuyan shijiao xia de Hanyu zhongdongju yanjiu [Chinese middles: A cross-linguistic perspective]. Dangdai Yuyanxue [Contemporary linguistics] 1. 83-103.

Huang, C.-T. James. 1982. Logical relations in Chinese and the theory of grammar. Cambridge, MA: Massachusetts Institute of Technology dissertation.

Huang, C.-T. James. 1988. Wo pao de kuai and Chinese phrase structure. Language 64. 274-311.

Huang, C.-T. James. 1992. Complex predicates in control. In Richard K. Larson, Sabine Iatridou, Utpal Lahiri \& James Higginbotham (eds.), Control and grammar, 109147. Dordrecht: Kluwer.

Huang, C.-T. James. 1997. On lexical structure and syntactic projection. Chinese Languages and Linguistics 3. 45-89. 
Huang, C.-T. James. 2006. Resultatives and unaccusatives: A parametric view. Bulletin of the Chinese Linguistic Society of Japan 253. 1-43.

Huang, C.-T. James. 2015. On syntactic analyticity and parametric theory. In Y.-H. Audrey Li, Andrew Simpson \& W. -T. Dylan Tsai (eds.), Chinese syntax in a cross-linguistic perspective, 1-50. Oxford: Oxford University Press.

Huang, C.-T. James, Y.-H. Audrey Li \& Yafei Li. 2009. The syntax of Chinese. Cambridge: Cambridge University Press.

Irwin, Patricia. 2019. How do you smile along a path? The Linguistic Review 36(3). 343-363. Jackendoff, Ray S. 1972. Semantic interpretation in generative grammar. Cambridge, MA: MIT Press.

Jensen, John T. 1990. Morphology: Word structure in generative grammar. Amsterdam: John Benjamins Publishing Company.

Katz, Graham. 2008. Manner modification of state verbs. In Louise McNally \& Christopher Kennedy (eds.), Adjectives and adverbs, 220-248. Oxford: Oxford University Press.

Kayne, Richard. 1994. The antisymmetry of syntax. Cambridge, MA: MIT Press.

Kearns, Kate. 2011. Semantics, 2nd edn. New York: Palgrave Macmillan.

Keyser, Sameul J. \& Thomas Roeper. 1984. On the middle and ergative constructions in English. Linguistic Inquiry 15. 381-416.

Kong, Lingda. 1986. Guanyu dongtai zhuci guo he guo $_{2}$ [On dynamic auxiliary guo and guo $_{2}$ ], Zhongguo Yuwen [Studies of the Chinese language] 4. 272-276.

Lee, Thomas Hun-Tak \& Zhuang Wu. 2019. The acquisition of nominal structure, word order and referentiality in Chinese: Corpus and experimental findings on the numeral phrase. In Jianhua Hu \& Haihua Pan (eds.), Interfaces in grammar, 301-340. Amsterdam \& Philadelphia: John Benjamins.

Levin, Beth \& Malka Rappaport Hovav. 2005. Argument realization. Cambridge: Cambridge University Press.

Li, Charles N. \& Sandra A. Thompson 1981. Mandarin Chinese: A functional reference grammar. Berkeley, CA: University of California Press.

Li, Liding. 1963. Dai “de" zi de buyu ju [Sentences with de-complements], Zhongguo Yuwen [Studies of the Chinese language] 5. 396-410.

Li, Y-.H. Audrey. 1987. Duration phrases: Distributions and interpretations. Journal of the Chinese Language Teachers Association 22(3). 27-65.

Li, Y.-H. Audrey. 1998. Argument determiner phrases and number phrases. Linguistic Inquiry 29. 693-702.

Lin, Jimmy. 2004. Event structure and the encoding of arguments: The syntax of the Mandarin and English verb phrase. Cambridge, MA: Massachusetts Institute of Technology dissertation.

Lin, Tzong-Hong Jonah. 2001. Light verb syntax and the theory of phrase structure. Irvine, CA: University of California, Irvine dissertation.

Lin, Tzong-Hong Jonah. 2011. Finiteness of clauses and raising of arguments in Mandarin Chinese. Syntax 14. 48-73.

Liu, Yuehua. 1988. Dongtai zhuci " $g u o_{2}, g u o_{1}$, le" yongfa bijiao. Yuwen Yanjiu [Linguistic Research] 1. 6-16.

Lü, Shuxiang. 1987. Shuo "sheng" he "bai" [On win and lose]. Zhongguo Yuwen [Studies of the Chinese language] 1. 1-5. 
Lü, Shuxiang (ed.). 1999. Xiandai Hanyu baibai ci [On eight hundred words in Modern Chinese], rev. edn. Beijing: The Commercial Press.

Lu, Yingshun. 1991. Tantan $l e_{1}$ he $l e_{2}$ de qubie fangfa [On how to distinguish $l e_{1}$ and $l e_{2}$ ]. Zhongguo Yuwen [Studies of the Chinese language] 4. 275-278.

Ma, Xiwen. 1987. Yu dongjieshi dongci youguan de mouxie jushi [Some VR-releated constructions]. Zhongguo Yuwen [Studies of the Chinese language] 6. 424-441.

Maienborn, Claudia. 2005. On the limits of the Davidsonian approach: The case of copular sentences. Theoretical Linguistics 31. 275-316.

Marantz, Alec. 1984. On the nature of grammatical relations. Cambridge, MA: MIT Press.

Marantz, Alec. 1988. Clitics, morphological merger, and the mapping to phonological structure. In Michael Hammond \& Michael Noonan (eds.), Theoretical morphology, 253-270. San Diego, CA: Academic Press.

Mare, María. 2018. Issues on word formation. The case of Latin circum. The Linguistic Review 35(1). 121-159.

Martinović, Martina. 2019. Interleaving syntax and postsyntax: Spellout before syntactic movement. Syntax 22(4). 378-418.

Matushansky, Ora. 2006. Head movement in linguistic theory. Linguistic Inquiry 37(1). 69-109.

Mittwoch, Anita, Rodney Huddleston \& Peter Collins. 2002. The Clause: Adjuncts. In Rodney Huddleston \& Geoffrey K. Pullum (eds.), The Cambridge grammar of the English language, 663-784. Cambridge: Cambridge University Press.

Packard, Jerome L. 2000. The morphology of Chinese: A linguistic and cognitive approach. Cambridge: Cambridge University Press.

Pan, Haihua \& Jingquan Han. 2005. Xianxing feibinge dongci jiegou de jufa yanjiu [The syntax of surface unaccusative constructions] Yuyan Yanjiu [Language research] 3. 1-13.

Pan, Victor Junnan. 2017. Derivation of the apparent narrow scope of sentence-final particles in Chinese. Studies in Chinese Linguistics 39(2). 99-125.

Pan, Victor Junnan. 2019a. System repairing strategy at interface wh-in-situ in Mandarin. Chinese. In Jianhua Hu \& Haihua Pan (eds.), Interfaces in grammar, 133-166. Amsterdam \& Philadelphia: John Benjamins.

Pan, Victor Junnan. 2019b. Architecture of the periphery in Chinese: Cartography and minimalism. London \& New York: Routledge.

Paul, Waltraud. 2014. Why particles are not particular: Sentence-final particles in Chinese as heads of a split CP. Studia Linguistica 68(1). 77-115.

Paul, Waltraud \& John Whitman. 2008. Shi...de focus cleft in Mandarin Chinese. The Linguistic Review 25. 413-451.

Pensalfini, Robert. 1997. Jingulu grammar, cictionary, and texts. Cambridge, MA: Massachusetts Institute of Technology dissertation.

Ramchand, Gillian. 2008. Verb meaning and the lexicon: A first-phase syntax. Cambridge: Cambridge University Press.

Ramchand, Gillian. 2013. Argument structure and argument structure alternations. In Marcel den Dikken (ed.), The Cambridge handbook of generative syntax, 265-321. Cambridge: Cambridge University Press. 
Rappaport Hovav, Malka \& Beth Levin. 1998. Building verb meanings. In Butt Miriam \& Wilhelm Geuder (eds.), The projection of arguments: Lexical and compositional factors, 97-134. Standford, CA: CSLI Publications.

Rappaport Hovav, Malka \& Beth Levin. 2001. An event structure account of English resultatives. Language 77. 766-797.

Richards, Norwin. 2016. Contiguity theory. Cambridge, MA: MIT Press.

Roberts, Ian. 1986. The representation of implicit and dethematized subjects. Foris: Dordrecht.

Rong, Jin. 2006. Hanyu kouyuti shoushi qianzhiju [Patient-subject constructions in spoken Chinese] Beijing Daxue Xuebao [Journal of Peking University] (Philosophy and Social Sciences) 4. 114-120.

Simpson, Andrew \& Zoe Xiu-Zhi Wu. 2002. From D to T - Determiner incorporation and the creation of tense. Journal of East Asian Linguistics 11. 169-209.

Stroik, Thomas. 1992. Middles and movement. Linguistic Inquiry 23. 127-137.

Sung, Kou-Ming. 1994. Case assignment under incorporation. Los Angeles: University of California, Los Angeles dissertation.

Talmy, Leonard. 2000. Toward a cognitive semantics. Vol. 2, Typology and process in concept structuring. Cambridge, MA: MIT Press.

Tang, C.-C. Jane. 1990. Chinese phrase structure and the extended X'-theory. Ithaca, New York: Cornell University dissertation.

Tang, C.-C. Jane. 2001. Functional projections and adverbial expressions in Chinese. Language and Linguistics 2. 203-241.

Tang, Sze-Wing. 2006. Hanyu fangyan shoushi huatiju leixing de canshu fenxi [A parametric approach to the typology of subtopics in Chinese dialects]. Yuyan Kexue [Linguistic sciences] 6. 3-11.

Tang, Sze-Wing. 2019. Xingshi Hanyu jufaxue [Formal Chinese syntax], 2nd edn. Shanghai: Shanghai Educational Publishing House.

Teng, Shou-Hsin. 1979. Remarks on cleft sentences in Chinese. Journal of Chinese Linguistics 7(1). 101-114.

Ting, Jen. 2006. The middle construction in Mandarin Chinese and the presyntactic approach. Concentric Studies in Linguistics 32(1). 89-117.

Travis, Lisa. 1988. The syntax of adverbs. McGill Working Papers in Linguistics: Special Issue on Comparative Germanic Syntax. 280-310.

Trotzke, Andreas. 2015. Rethinking syntactocentrism: Architectural issues and case studies at the syntax-pragmatics interface. Amsterdam: John Benjamins Publishing Company.

Truckenbrodt, Hubert. 1999. On the relation between syntactic phrases and phonological phrases. Linguistic Inquiry 30. 219-256.

Tsai, W.-T. Dylan. 2001. On subject specificity and theory of syntax-semantics interface. Journal of East Asian Linguistics 10. 129-168.

Tsai, W.-T. Dylan. 2007. Chongwen "weishenme wen zenmeyang, zenmeyang wen weishenme"- Tan Hanyu yiwenju he fanshenju zhong de neiwai zhuangyu ['The hows of why and the whys of how' revisited: On inner and outer adverbials in Chinese interrogative and reflexive sentences]. Zhongguo Yuwen [Studies of the Chinese language] 3. 195-207. 
Tsai, W.-T. Dylan. 2008a. Left periphery and how-why alternations. Journal of East Asian Linguistics 17(2). 83-115.

Tsai, W.-T. Dylan. 2008b. Tense anchoring in Chinese. Lingua 118. 675-686.

Wang, Changsong. 2014. Exploring the interface between syntax and morphology- $A$ case study of de. Beijing: Beijing Language and Culture University dissertation.

Wang, Changsong. 2017. On some asymmetries and derivation of potential de construction in Chinese. Language and Linguistics 18(4). 647-698.

Wang, Changsong \& Wei Chin. 2016. Jufa-yinxi jiekou shiyuxia de rongnaju yanjiu [A study on flip-flop sentences in Chinese from the syntax-phonology interface]. Yuyan Jiaoxue yu Yanjiu [Language teaching and linguistic studies] 6. 48-58.

Wang, Changsong \& Wei Chin. 2018. Cong fenbushi xingtaixue kan Hanyu "V+shiliang duanyu" disanzhong yuyi jiedu de jufa gouzao [A DM-based inquiry into the syntactic structure of the third reading of "V+ DurP" in Chinese]. Shijie Hanyu Jiaoxue [Chinese teaching in the world] 4. 456-474.

Wang, Jianian. 2008. Shoushi zhuyuju de shengcheng liju [The generative motivation of the Patient-Subject sentences]. Yuyan Jiaoxue yu Yanjiu [Language teaching and linguistic studies] 3. 45-49.

$\mathrm{Wu}, \mathrm{C} . \mathrm{-H}$. Teresa. 2004. On $d e / b u$ and the syntactic nature of resultative verbal compounding. Language and Linguistics 5(1). 271-329.

Xiong, Jiajuan. 2018. Chinese middle constructions: Lexical middle formation. Beijing: Peking University Press \& Singapore: Springer Nature Singapore Pte Ltd.

Yang, Daran \& Gong Cheng. 2018. Hanyu huodonglei dongci de lunyuan jiaoti jiqi jufa gouzao [The argument alternation of Chinese activity verbs and their syntactic constructions]. Zhongguo Yuwen [Studies of the Chinese language] 6. 657-671.

Yip, Po-Ching \& Don Rimmington. 2016. Chinese: A comprehensive grammar, 2nd edn. London \& New York: Routledge.

Zhan, Renfeng. 1992. Shoushi zhuyuju (ming-dong shi) de shibie [On the demarcation of patient-subject (NP-V) sentences]. In Editorial Office of Studies of the Chinese Language (ed.), Yufa yanjiu he tansuo [Grammar research and inquiry] 6. 190-204. Beijing: Yuwen Chubanshe.

Zhu, Dexi. 1982. Yufa jiangyi [Lecture notes in Chinese grammar]. Beijing: The Commercial Press.

\section{Changsong Wang}

Mailing address: School of Foreign Languages, Beijing Institute of Technology, No. 5 Zhongguancun South Street, Haidian District, Beijing, 100081, China

Email: $\quad$ cswang@bit.edu.cn Mingming Zheng

Mailing address: School of Foreign Languages, Beijing Institute of Technology, No. 5 Zhongguancun South Street, Haidian District, Beijing, 100081, China

Email:

Received: zheng_mingming1994@163.com

Accepted:

April 16, 2019

April 14, 2020 


\title{
句法 - 形態接口視域下的漢語受事主語句研究
}

\author{
汪昌松 $^{1,2}$ 、鄭明明 ${ }^{1}$ \\ 北京理工大學 ${ }^{1}$ \\ 工信部語言工程與認知計算重點實驗室 ${ }^{2}$
}

\section{提要}

學界對漢語受事主語句的性質和推導一直存有爭議。本文研究發現該類結構中存在 方式狀語修飾限制, 在用 “怎麼” 進行提問時也得不到方式解讀。基於此, 本文從 句法 - 形態接口視角來對該類結構做出新探索。與先前分析不同, 我們認為受事主 語中的顯性動詞 $\mathrm{V}$ 並不是句子的主要謂詞, 而只是一個動詞詞根, 該詞根在句法 操作完成之後才以外部形態合併的方式引入句子推導。受事主語句的主要動詞實 為表變化義的隱性輕動詞 $\emptyset_{\mathrm{BEC}}$, 它選擇 NP 為標示語, RP 為補足語。體標記短語 AspP 以詞経 “了” 為核心詞, “了” 選擇 BECP 為補足語。由於 EPP 作用, NP 由 Spec, BecP 移至 Spec, TP 。句法操作完成後進入音韻部門（形態操作），表結果 的 $R$ 通過核心詞移位移至 $\emptyset_{\mathrm{BEC}}$ 處以滿足其詞綴特性, 然後動詞詞根再與 $\mathrm{R}-\emptyset_{\mathrm{BEC}}$ 進 行外部形態合併, 指涉該狀態變化的方式。為了滿足體標記 “了” 的詞経特性, $\mathrm{V}-\mathrm{R}-\emptyset_{\mathrm{BEC}}$ 繼續上移至 “了”處, 從而生成受事主語句。省略的受事主語句也可以採 用類似的句法 - 形態接口分析。本研究表明隱性輕動詞和形態在派生漢語特定結構 時可能會相互協助、一起發揮作用。

\section{關鍵詞}

詞根外部形態合併, 句法 - 形態接口, 方式狀語修飾限制, 词根, 受事主語句 